\title{
Do CDS maturities matter in the evaluation of the information content of regulatory banking stress tests? Evidence from European and US stress tests.
}

\author{
Amavi AGBODJI*, Emmanuelle NYS*, Alain SAUVIAT* \\ *Université de Limoges, LAPE, 5 rue Félix Eboué, 87031 Limoges Cedex 1, France
}

Preliminary version - September 06, 2019

A more recent version of this paper (with substantial modifications) has been published: Agbodji, A., Nys, E., Sauviat, A., 2021. "Do CDS maturities matter in the evaluation of the information content of regulatory banking stress tests? Evidence from European and US stress tests", Revue Economique, 72(I), 65-102
A
B S
T R
A
C $\mathrm{T}$

This paper questions the relevance of using only the 5-year maturity CDS spreads to examine the CDS market response to the disclosure of a regulatory stress test results. Since the stress testing exercises are performed on short-term forward-looking stressed scenarios (1 to 3 years), we assume that short-term CDS maturities (from 6-month to 3-year) should better reflect the CDS market response compared to the 5-year maturity. Based on ten regulatory stress tests carried out in Europe and in the US in the time period from 2009 to 2017, we analyze the CDS market response by investigating its reaction through all the different CDS maturities. Our results show that after the results' disclosure, the CDS market reacts by correcting the CDS spreads of tested banks (upward or downward correction), at the level of all maturities. More precisely, we evidence that for a given stress test, the nature of the correction (upward or downward) is the same for all CDS maturities while the extent of the correction differs between shortterm maturities (from 6-month to 3-year) and the 5-year maturity or more. Indeed, we find that the extent is higher on short-term maturities and in most cases, the lower the maturity of the CDS, the higher the extent of the correction (i.e. the stronger the market reaction). We therefore argue that the only use of the 5-year maturity is not suitable. Short-term CDS maturities matter since they better reflect the CDS market response. Also, the use of these short-term maturities show that the information content of the different stress tests is more diverse than what is highlighted in the existing literature.

Keywords: Regulatory stress tests, CDS maturities, Market reaction, Event study, Disclosure JEL Classification Numbers: G00, G14, G21, G28 


\section{Introduction}

A regulatory stress testing exercise is an important banking supervision tool whose main objective is to assess and analyze the resilience of participating banks to hypothetical extreme but plausible stressed scenarios. These latter simulate crisis situations (with different levels of severity) characterized by a recession at the national and global levels, a very high unemployment etc. At the end of the test, and for each of the scenarios, thousands of data that reflect the financial health of each participating bank throughout these crisis situations (including data on capitalization, solvency, market risk, credit risk and liquidity risk) are disclosed in a very detailed way, thus providing reliable information on tested banks' situation (strength, resilience, risks...). However, CDS spreads precisely reflecting the market perception of banks' situation, stress test results' disclosure may be more informative for credit default swap market. Most of empirical papers that study stress test impacts on CDS performance show that new and relevant information was revealed by highlighting significant reactions from the CDS market around the stress tests' key event dates (especially the results' disclosure date).

This paper questions the relevance of using only the 5-year maturity CDS spreads to examine the CDS market response to the disclosure of a regulatory stress test results. Is the maturity of 5-year the one that best reflects the CDS market response? To attempt to answer to this question, we examine whether the CDS market response is the same for all CDS maturities or whether it differs. In other words, we investigate whether the short-term maturities of CDS (6-month, 1-year, 2-year and 3-year maturities) provide the same information as the commonly used 5-year maturity or more.

Our research is motivated by the following. To estimate the CDS market response to a regulatory stress testing exercise (so to measure the impact and the informative value of a stress test), the literature almost systematically uses the 5-year maturity CDS spreads (among others, Morgan et al., 2014; Neretina et al., 2014; Flannery et al., 2017; Georgescu et al., 2017 and Ahnert et al., 2018) since it is the most liquid segment of the market (Annaert et al., 2013; Völz \& Wedow, 2011). However, is the maturity of fiveyear the one that best reflects the response of the CDS market? Since the hypothetical forward-looking scenarios of a stress testing exercise have a time horizon of 3 years, 
and since the disclosed results (on participating banks' resilience and financial health under these "dark" scenarios) only cover these 3 years, we assume that short-term CDS maturities should be more relevant to assess the market response rather than the 5year maturity. In other words, the short-term maturities of CDS (6-month, 1-year, 2year and 3-year maturities) should be more relevant because the stress testing exercises are performed on short-term forward-looking stressed scenarios (1, 2 and 3 years). Therefore, we assume that short-term CDS maturities should better reflect the CDS market response, compared to the 5-year maturity or more.

To our best knowledge, no paper has in the past investigated this issue. Our study is therefore important since it will examine whether the CDS market response is the same from one maturity to another. Consequently, it will examine whether the 5-year CDS maturity is the one that best reflects the market response; and if not, it will identify the suitable maturities. Future papers can take this into account when examining the CDS market response to stress tests.

Applying an event study methodology on tested banks' CDS spread returns, we estimate the CDS market response (the Cumulative Average Abnormal Returns CAARs) to the disclosure of the results of ten European and US regulatory stress tests, carried out in the time period from 2009 to 2017. We perform these estimates using daily data on senior CDS spreads and considering each of the eight CDS maturities (6month, 1-year, 2-year, 3-year, 4-year, 5-year, 7-year and 10-year maturities) in order to examine whether the CDS market response is the same from one maturity to another.

Our empirical results show that following the release of the results of a given stress test, with the new relevant information provided, the CDS market reacts by correcting the CDS spreads of tested banks (upward or downward correction), at the level of all maturities. More precisely, we evidence that for a given stress test, the nature of the correction (upward or downward) is the same for all CDS maturities while the extent of the correction differs from one maturity to another. Indeed, we find that for a given stress test, the CDS market may react strongly on one maturity (very high CAARs in absolute value) and weakly on another one (very low CAARs in absolute value) after the disclosure. According to our results, it seems to react more strongly on short-term CDS maturities (from 6-month to 3-year) than on 5-year maturity or more. And in most 
cases, the lower the maturity of the CDS, the stronger the market reaction i.e. the higher the extent of the correction. We therefore argue that the only use of the 5-year maturity CDS spreads in the examination of the CDS market response to stress test is not suitable. Short-term CDS maturities matter since they better reflect the market response. In other words, taking them into account will allow a better appreciation of the market response. Secondly, short-term CDS maturities allow to better judge the difference between several stress tests according to their quality (compared to $5 \mathrm{Y}$ maturity or more). Also, they better reflect the assessment by the market of tested banks' default risks.

Being the first to perform such empirical investigations, our paper attempts to contribute to the existing literature on regulatory banking stress tests, more precisely the literature on the impact, the information content and the effectiveness of stress tests (Petrella and Resti, 2013; Morgan et al., 2014; Neretina et al., 2014; Flannery et al., 2017; Georgescu et al., 2017 and Ahnert et al., 2018). It attempts to further develop the understanding of the CDS market response to a stress testing exercise. Secondly, our paper also contributes to the strand of the literature on banking opacity (among others, Flannery and Houston, 1999; Jordan et al., 2000; Morgan, 2002; Flannery et al., 2010) since we evidence that following the disclosure of stress test results, the CDS market, considering the new relevant information provided corrects (adjusts) the CDS spreads of participating banks, at the level of all maturities. This correction from the market highlights the existence of a banking opacity, i.e. the impossibility for market participants to have access to reliable financial data on banks. Our paper finally contributes to the debate on transparency in banking supervision (Jordan, 2000; Dudley, 2009; GAO, 2010 and Goldstein and Sapra, 2011) since our results show that more disclosure about banks' situation and resilience can help market participants to better assess the value and the risks of banks and thus, to better discriminate them.

The remainder of our paper is organized as follows: in Section 2, we provide an overview of the existing literature on the CDS market reaction around stress tests' key event dates. In Section 3, we first present a brief overview of the regulatory stress tests that we consider. We then describe the sample, the data and the empirical methodology employed to perform our investigations. The presentation of the results 
follows in Section 4 with some robustness tests while Section 5 discusses our findings and proposes some recommendations. Finally, Section 6 concludes the paper.

\section{Related literature and research question}

Banks are intrinsically opaque because of their intermediation function. Investors and savers place their money in banks which are supposed to lend to borrowers after a rigorous screening, and with an intensive monitoring (Diamond, 1983). But the risks taken by banks in this intermediation process are hard to observe for investors and savers. Indeed, if banks were completely transparent, there should be no market reaction to the release of supervisory information; but it is not the case since the release of such information induce substantial and significant movements in stock prices (Berger and Davies, 1998; Flannery and Houston, 1999; Jordan, 2000). Therefore, several empirical papers have been interested in the impact and the informative value of regulatory banking stress tests. Almost all of them examines at least the stock market reaction around these stress tests' key event dates but there is an emerging literature on the effects of regulatory stress tests on CDS performance.

Morgan et al. (2014) for example were interested in the 2009 US SCAP effects. Using a standard event study methodology, they investigate whether this latter produced useful and valuable information for the market by considering two groups of banks: the GAP banks and the NO GAP banks ${ }^{1}$. In summary, they show that the test provided useful information to the market. More precisely, they evidence that prior to the test, financial markets were largely able to identify the banks without capital gaps and those which are under-capitalized; what they didn't know was the exact amount of capital required for under-capitalized banks. Therefore, at the results' disclosure, the market was surprised and reacted significantly by correcting banks' stock prices (which increased) and spreads of CDS. These latter decline, particularly for undercapitalized banks whose spreads fell by 59 basis points relative to spreads for NO GAP banks. Based on the US banking stress tests from 2009 to 2015 (SCAP, CCAR and DFAST), Neretina et al. (2015) complement the work of Morgan et al. (2014) by

\footnotetext{
${ }^{1}$ The GAP banks are those with capital gaps while the NO GAP banks are those without capital gaps.
} 
reassessing their findings and investigating whether their conclusions are also valid for other stress tests. In contrast with Morgan et al. (2014) findings, they show that the disclosure of the 2009 US SCAP results had no effect on equity returns. But they evidence on the other hand a decline in CDS spreads, especially for NO GAP banks (with an average CAR of $-55,43$ basis points). For the stress tests carried out after the SCAP, they find evidence that CDS spreads declined in response to the publication of stress test results only in 2012 and 2013.

Then, Flannery et al. (2017) examine changes in banks' stock prices, trading volumes and CDS spreads around several disclosure dates of regulatory stress test results in the US, in the time period from 2009 to 2015. Unlike previous studies, they don't use a standard event study methodology since they argue that this latter is not suitable for measuring the true informative value of a stress testing exercise because of inappropriate assumptions embedded in it. Using their "customized" event study methodology, they show that the nine tests produce new and valuable information not only about stress-tested banks' situation, but also about non-stress-tested banking companies; the tested sample's reaction almost always exceeding the one of the nonstress-tested sample. More precisely, using an absolute cumulative abnormal CDS Spread (|CACDSI), they evidence that the CDS spreads of stress tested banks change abnormally and significantly around all the stress test disclosure dates considered (especially around the 2009 SCAP disclosure date). Then considering respectively the tested and the non-tested banks' group average ICACDSI, they highlight significant differences between them thus confirming the fact that the response of the tested sample almost always exceeds the one of the non-stress-tested sample.

Like in the US, European banking authorities have also performed several regulatory stress testing exercises since 2009 and many empirical papers have been interested in the effects of their results' disclosure on CDS markets.

Georgescu et al. (2017) try to determine empirically if European regulatory stress tests are really useful (if they provide new and valuable information to the market), basing on the 2014 and 2016 EBA-ECB stress tests. They therefore assess the reaction of market participants by estimating the cumulative abnormal returns (CAR) using tested banks' CDS spreads and stock prices, and sovereign CDS spreads. For these estimates, they 
employ an event study methodology, around several event dates (e.g. announcement dates, disclosure dates etc...). With somewhat mixed results, they argue that stress tests provide new information to the market. More precisely, they find that new and useful information was revealed to the CDS market participants around the announcement of the test (only in 2014), the announcement of the key features (in 2014 and 2016) and following the results' disclosure (only in 2016); new information that was immediately integrated in tested banks' CDS spreads as reflected in statistically significant abnormal CDS returns. Authors also find that the publication of stress test results allows markets to better discriminate between "good" (strong) banks and "bad" (weak) banks. Indeed, authors show that under the adverse scenario, banks that lost a large part of their Common Equity Tier 1 ratio (what prove their weakness) were been punished by the market; following the results' disclosure, these latter reported significantly higher positive abnormal CDS returns compared to better performing banks. Similarly, analyzing the impact of stress testing results' publication on bank's equity and CDS performance, Ahnert et al. (2018) also come to the same conclusion. Indeed, performing their empirical investigations on a larger number of regulatory stress tests (ten tests including six US CCAR and four EBA/ECB stress tests in the time period between 2010 and 2017), authors show that the results' disclosure provide new information to market participants and reduce bank opacity by improving the quality and the quantity of information available on tested banks' situation. Hence, it allows markets to better discriminate between strong banks (which were rewarded) and weak banks (which were sanctioned). Indeed, they highlight that following the results' release, strong banks have better funding costs and higher stock prices unlike weak ones. More precisely, they show that banks that passed the test show significant and positive abnormal stock returns and smaller CDS spreads (with an abnormal CDS returns of -83 basis points). In contrast, those that failed experience significant and negative abnormal stock returns and higher CDS spread (172 basis points). Concerning the announcement date, they find that banks that are announced to be stress tested surprisingly experience on average wider CDS spreads (78 basis points of abnormal CDS returns). Performing finally a multivariate regression analysis, they evidence that bank's asset quality and return on equity are significant predictors of the pass/fail outcome of a bank during a stress test. 
To examine the CDS market response to regulatory stress tests, all the above papers used the 5-year maturity contract as it is generally considered to be the most liquid segment of the market (Annaert et al., 2013; Völz \& Wedow, 2011). However, we question the relevance of using only the 5-year maturity contract in the examination of the CDS market response. Indeed, we assume that the disclosure of stress test results should be more relevant (should more impact) for spreads of CDS whose maturities are less than or equal to 3 years. Since stress testing exercises are performed on two or three-year forward-looking scenarios, we assume that these short-term CDS maturities should better reflect the CDS market response compared to the 5-year maturity. Therefore, by considering several maturities' CDS spreads, our goal is to investigate whether the CDS market response is the same from one maturity to another after the disclosure. In other words, is the market reaction the same depending on the maturity considered? If not, does the 5-year maturity correctly reflect the market response? Does a shorter maturity give a better information?

\section{Sample, Data and Methodology}

In this section, we first present the different (US and European) regulatory stress tests that we consider for our investigations. Then, we describe respectively the sample on which this study is based, the data used to perform our investigations and the methodology employed to estimate the market reaction. Finally, we analyze the liquidity of our data (CDS spreads) at the level of all maturities.

\subsection{Regulatory stress testing exercises in Europe and in the US}

To perform our empirical investigations on the CDS market response to stress test results' disclosure, we consider all relevant regulatory stress tests carried out in Europe and in the US, in the time period from 2009 to 2017.

In Europe, five stress testing exercises were carried out during this period. The first and the second ones that took place respectively in 2009 and 2010 was conducted by 
the Committee of European Banking Supervisors (CEBS) ${ }^{2}$. The next one was conducted in 2011 by the European Banking Authority (EBA), on the same sample of banks as the 2010 test. The remaining tests were also performed by the EBA, respectively in 2014 and $2016^{3}$ in close cooperation with the European Central Bank (ECB) within the Single Supervisory Mechanism (SSM). Among these five tests, we will not consider the 2009 one in our study since its aim was not to assess banks individually, but to evaluate the resilience of the European banking industry in aggregate, without publication of the participating banks' names.

In the US, the first regulatory stress test was the 2009 Supervisory Capital Assessment Program (SCAP). Nineteen US bank holding companies (representing two-thirds of the US banking system's assets) participated in this test which was unprecedent in terms of supervisory information disclosure. Since then, the Federal Reserve (FED) formally introduced a regulatory framework to annually assess, regulate, and supervise US BHCs. This supervisory assessment consists of two related programs: The Comprehensive Capital Analysis and Review (CCAR) and the Dodd-Frank Act stress tests (DFAST). The first program involves both a qualitative and a quantitative evaluation. More precisely, the FED performs for each participating BHC a qualitative analysis of its internal capital planning processes and governance, and a quantitative assessment of its capital positions (capital adequacy). In the other side, like the SCAP, the DFAST program examines how banks' capital levels would evolve under severely adverse economic conditions (stressed period) in order to assess their ability to absorb possible future shocks. The first CCAR took place in 2011 while the first DFAST took place in $2013^{4}$.

\footnotetext{
2 The 2009 CEBS stress test was conducted on a sample of 22 major European cross-border institutions representing on a consolidated basis, $60 \%$ of the total assets of the EU banking sector. At the end of the test, supervisors did not disclose the names of the 22 participating banks, nor the detailed results of the test. The 2010 and 2011 exercises were conducted on a sample of 91 European banks representing together $65 \%$ of the total assets of the EU banking sector. Unlike the 2009 test, details data on each tested bank were disclosed at the end of these two tests.

3 The 2014 stress test includes 123 European banking groups (representing more than $70 \%$ of the EU banking industry assets) while the 2016 exercise was carried out on a sample of 51 banking groups. The results of these two tests were also disclosed in a very detail way.

${ }^{4}$ The 2013, 2014 and 2015 DFAST was performed respectively on 18, 30 and 31 bank holding companies (BHCs). In 2016, 33 BHCs participated in the DFAST while they were 34 for the 2017 exercise.
} 
For the US, this study focuses on the DFAST program as it is the one that assesses banks' financial health under hypothetical forward-looking "dark" scenarios (like the SCAP and all European tests), unlike the CCAR program. In addition, the results of the DFAST stress tests are disclosed approximately a week before the corresponding CCAR results.

\subsection{Capturing the CDS market response to stress test results' publication.}

\subsubsection{Sample Selection and Data Description}

Our overall initial sample includes all the banks that have been tested in at least one of our considered stress tests. More precisely, the US initial sample includes 34 banks that have been tested at least once by the Federal Reserve between 2009 and 2017. The European sample is comprised of 123 banks (across 22 EU countries) that have been tested by the CEBS (in 2010) and/or the EBA (in 2011, 2014 and 2016).

Then, to perform our investigations, we collect daily data on senior CDS spread from Bloomberg ${ }^{\mathrm{TM}}$, for each of the participating banking institutions in our initial sample and for all maturities. We get these data exclusively from the CMA New York source, which provides closing bid and ask CDS quotes. However, CDS spreads data are not available for all banks; for some of them, tradable CDS doesn't exist while it exists for others but with no available data. At the end, in our US final sample, the number of tested banks with available information on tradable credit default swap range from 9 to 12 per stress test. In Europe, this number varies from 33 to 50 per stress test ${ }^{5}$. All of these companies are banks, with the exception of 2 US companies ${ }^{6}$ which belongs to the "Diversified Financial Services" industry. Appendix A.1 provides an overview of the banks included in our final sample, test by test in the US (Panel A) and in Europe (Panel B). Panel C shows the different countries represented in the EU final sample with the number of banks per country.

As Indices for bank CDS, following Norden and Weber (2004), Morgan et al. (2014), Neretina et al. (2014), Flannery et al. (2017) and Ahnert et al. (2018), we employ the

\footnotetext{
${ }^{5}$ In Europe as in the US, the number of stress tested banks varies from one test to another.

${ }^{6}$ Ally Financial Inc. and American Express Co.
} 
Markit CDX North America Investment Grade Index for the US. For Europe, we use the Markit iTraxx Europe Investment Grade index. Both are composed of 125 equally weighted credit default swaps on US (European) investment grade entities, distributed among several sub-indices (Financials, Non-Financials and High Volatility). We then collect daily data from Bloomberg ${ }^{\text {тм }}$ (CMA New York source) for each of these two indexes, but not for all maturities. Indeed, only four maturities are available $(3,5,7$ and 10 years). Therefore, we compute the $4 \mathrm{Y}$ daily CDX spreads for each index by taking the average between the $3 Y$ and the 5Y CDX spreads, at the level of each date. For the remaining unavailable maturities (6M, 1 and 2 year), we assigned them the spreads of the nearest available maturity to perform our investigations (so the spreads of the $3 Y$ maturity).

\subsubsection{Research Design and Methodology}

In order to investigate whether the market reaction is the same depending on whether one considers the short-term or the long-term CDS maturities, we employ an event study methodology (described for example in Brown and Warner (1985) and Campbell, Lo, and MacKinlay (1997)) that has been extensively used in the regulatory stress test literature.

More accurately, to capture the CDS market reaction to the publication of a given stress test results, we compute the Cumulative Average Abnormal (CDS) Returns CAARs of the group of tested banks over a relevant window around the disclosure date ("event window"); the CAARs being an estimation of the impact of the stress test outcomes' publication on the group of participating banks' spreads.

Then, to check whether the market reaction is the same from one maturity to another, we estimate for each stress test eight different CAARs considering each of the eight CDS maturities. In other words, we apprehend the response of the market using not only the $5 \mathrm{Y}$ maturity data (as previous papers), but also all the remaining maturities data in order to highlight possible differences in reactions depending on the maturity considered. 


\subsubsection{Events and Event dates}

In our study, for a given stress test, we consider as "event" the disclosure of its results. Following (among others) Flannery et al. (2017) and Ahnert et al. (2018), we will not consider as "event date" the stress test results' publication date but rather the next trading day. Indeed, the results are published either on a trading day but after market closing (in the US as in Europe), or during a non-trading day (as it was the case for the 2014 ECB-EBA stress test). Therefore, analytically, the actual event date is not the results' publication date, but rather the following trading day. Table 1 reports, for each stress testing exercise, the results' disclosure date and the corresponding event date in the US (Panel A) and in Europe (Panel B).

\subsubsection{Estimating the Cumulative Average Abnormal (CDS) Returns}

To obtain the CAARs of a group of banks over an event window, we measure first of all the abnormal return $\mathrm{AR}_{\mathrm{i}, \mathrm{t}}$ of each bank $\mathrm{i}$ in this group, on each date $\mathrm{t}$ of the event window. The abnormal return is the difference between the observed (actual) CDS spread return $R_{i t}$ and an expected (normal) return $\hat{R}_{i t .}$ This latter is the return that would be expected if the event did not take place. To estimate it, following the recent stress test literature (Campbell et al., 2010; Morgan et al., 2014; Neretina et al., 2014; Flannery et al., 2017 and Ahnert et al., 2018), we use a single-factor market model $^{7}$ (equation 1) over a 120-trading days window (consistent with MacKinlay (1997) suggestion and following Alves et al., 2015; Flannery et al., 2017 and Ahnert et al., 2018). Furthermore, since the stress testing exercises are generally performed each year (especially in the US), the choice of a 120-trading days estimation window allows us to prevent previous test events from influencing the estimation of the normal performance model parameters. The estimation window ends 10 trading days before the event as it goes from $\mathrm{t}-130$ to $\mathrm{t}-11$, $\mathrm{t}$ being the event date to be tested.

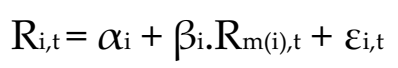

\footnotetext{
${ }^{7}$ Some papers on the same topic used a two or three-factor model to control for external factors. However, Ahern (2009) show that multifactor models produce only marginal benefits over a one-factor market model in predicting event day normal returns. This motivated us to use a one-factor market model, like previous papers.
} 
Therefore, the abnormal return or residuals $A R_{i, t}$ of a bank $i$, on date $t$ is given by:

$$
\mathrm{AR}_{\mathrm{i}, \mathrm{t}}=\mathrm{R}_{\mathrm{i}, \mathrm{t}}-\left[\hat{\alpha}_{i}+\hat{\beta}_{i}\left(\mathrm{R}_{\mathrm{m}(\mathrm{i}), \mathrm{t}}\right)\right]
$$

Following the work of Morgan et al. (2014), Flannery et al. (2017) and Ahnert et al. (2018), we compute $R_{i, t}\left(R_{m(i), t}\right)$ by transforming CDS (CDX) spreads into logarithmic returns with:

$$
R_{i, t}=\log \left(\frac{s_{i, t}}{s_{i, t-1}}\right) \quad \text { and } \quad R_{m(i), t}=\log \left(\frac{s_{m(i), t}}{S_{m(i), t-1}}\right)
$$

Where:

$R_{i, t}$ is the daily CDS spread return of bank $i$, on day $t$ and $R_{m(i), t}$ the daily CDX spread return of bank i's index, on day $t$. $S_{i, t}$ is the daily CDS MID spread of bank $i$, on day $t$ when $S_{m(i), t}$ is the daily CDX MID spread of bank i's index, on day t. $\hat{\alpha}_{i}$ and $\hat{\beta}_{i}$ are respectively the Ordinary Least Squares estimates of $\alpha_{\mathrm{i}}$ and $\beta_{\mathrm{i}}$. As we can see, $\alpha$ and $\beta$ are estimated separately for each bank $i$.

Then, since we are working on a pool of banks, we compute in a second stage the Average Abnormal Returns (AARt) which is the average of participating banks' abnormal returns on date $t$.

$$
\mathrm{AAR}_{\mathrm{t}}=\frac{\sum_{i=1}^{N} \mathrm{AR}_{i, t}}{N}
$$

Where $\mathrm{N}$ is the number of stress tested banks. We perform this computation for each date of the event window.

We focus on a three-day event window including the event date and the two following days $(t, t+1, t+2)$. Indeed, the use of a narrow window of three days, without taking into account pre-event dates ( $\mathrm{t}-2$ and $\mathrm{t}-1)$ allows reducing contamination problems which may bias the results of the analysis. In addition, this window incorporates the possibility that investors need time to properly assimilate all the implications of information revealed ${ }^{8}$, or that they react slowly to these information. Effectively, Krivin et al. (2003) show that the larger the surprise the longer it will take, for the market, to fully impound the information in the announcement.

\footnotetext{
${ }^{8}$ For each of the scenarios of a stress test, thousands of data that reflect the financial health of each participating bank throughout the (simulated) crisis situations are disclosed in a very detailed way.
} 
Finally, we calculate the Cumulative Average Abnormal (CDS) Returns CAARs by summing the Average Abnormal Returns AARt over our event window.

$$
\operatorname{CAAR}\left(t_{0}, t_{1}, t_{2}\right)=\sum_{t=t_{0}}^{t_{2}} \operatorname{AAR}_{t}
$$

\section{Statistical significance of CAARs}

After estimating a CAARs, we perform several significance tests in order to establish its statistical validity. In other words, we compute and analyze several statistics in order to "attest" whether the Cumulative Average Abnormal Returns that we estimated are significantly different from zero (and thus not the result of pure chance) or not.

A vast literature exists on significance tests in event study methodology. These latter can be categorized into two groups: parametric and non-parametric tests.

Parametric tests are based on the traditional t-test and rely on specific assumptions about the population parameters (normal distribution of CDS spreads in our case). To establish the statistical significance of our computed CAARs, we use three of them that we think, are the most relevant for our study.

The first one is the standardized abnormal return test developed by Patell (1976) who tried to adjust the classic t-test by standardizing the event window's ARs. However, many papers show later that a variance (volatility) increase on the event date can seriously bias the Patell test (among others, Brown and Warner, 1980, 1985) ${ }^{9}$. Therefore, Boehmer, Musumeci and Poulsen (1991) improve this latter by developing the standardized cross-sectional test (BMP test) which is robust to possible event-induced volatility and thereby outperforms the Patell test (Higgins and Peterson, 1998; Graham, Pirie and Powell, 1996; Harrington and Shrider, 2007; Campbell, Cowan and Salotti, 2010; Marks and Musumeci, 2017). It is widely considered as the default parametric test (Marks and Musumeci, 2017; Cowan, 2017). Nonetheless, it does not

\footnotetext{
${ }^{9}$ More recently, Marks and Musumeci (2017) find that even under ideal conditions when the event creates no additional variance, the Patell test remains biased.
} 
account for possible cross-sectional correlation of abnormal returns which can arise when all banks experience the event on the same date. To overcome this problem, Kolari and Pynnonen (2010) propose an adjustment of the BMP test that will account for cross-sectional correlation. It is the Kolari-Pynnonen test (or the adjusted standardized cross-sectional test).

However, since these three parametric tests assume that CDS spreads returns are normally distributed, they may underperform if this assumption is no longer respected. Hence, to avoid this situation, we compute in addition two non-parametric tests that are not relied on any underlying assumptions. These latter are particularly important in our study since CDS spreads are not normally distributed.

Investigating the accuracy and power of statistical tests applied to one-factor market model abnormal returns (with a single-market sample), Campbell, Cowan and Salotti (2010) find that the Cowan (1992) Generalized Sign test and the Corrado (1989) rank test are more powerful than two commonly used parametric tests, the BMP test and the Crude Dependence Adjustment CDA test (Brown and Warner; 1980, 1985). We therefore use as non-parametric test, the Cowan (1992) Generalized Sign test following Harvey et al. (2004), among others.

Based on the rank testing approach of Corrado (1989) and Corrado and Zivney (1992), Kolari and Pynnonen (2011) developed the "so-called" generalized rank (GRANK) non-parametric test which is, to our best knowledge, the most reliable and powerful test available. It dominates all parametric tests as well as the Corrado (1989) and the Corrado and Zivney (1992) rank tests (Kolari and Pynnonen, 2011). Consequently, it will be our second non-parametric test.

\subsection{Liquidity and Summary statistics of CDS spreads}

\subsubsection{Liquidity of spreads of CDS}

Liquidity in the CDS market reflects the ease with which traders can initiate a contract at an agreeable price (Tang and Yan, 2007). As mentioned above, most of the papers that were interested in the response of the CDS market (following stress tests) performed their investigations based solely on the 5-year maturity CDS contracts since 
these latter are generally considered in the literature as the most liquid compared to the other maturities' contracts. However, since this study is concerned with the market response at the level of all CDS maturities (not just the maturity of 5-year), we first focused on the liquidity of our data. Specifically, before starting our event studies, we first analyze the liquidity of CDS spreads of each maturity both at the bank level and at the index level.

It is difficult to find a single summary measure to capture the various facets of liquidity (adverse selection, search frictions, inventory costs...). Hence, to measure (estimate) the liquidity of CDS contracts, following Tang and Yan (2013), Annaert et al. (2013) and Samaniego-Medina et al. (2016), we use the Bid-Ask spread of the CDS quotes; i.e. the difference between ask and bid quote.

Our choice to use the bid-ask spread is primarily motivated by the fact that it is arguably the most widely used CDS liquidity proxy in finance. In addition, according to Bongaerts et al. (2011) and Tang and Yan (2010), there are significant correlations between the bid-ask spread and other liquidity proxies (e.g. number of quotes per CDS, data on trades or volume of orders).

Following Samaniego-Medina et al. (2016) and Arakelyan and Serrano (2016), we consider the absolute bid-ask spread (rather than the relative one) that we compute on a daily basis. According to Pires et al. (2011) and Coro et al. (2012), the absolute bidask spread is already a proportional measure. As liquidity increases, the size of the bid-ask spread narrows.

Panel A (Panel B) of Appendix A.2 provides the summary statistics of absolute bid-ask spreads in the US (Europe), at the aggregate level. As expected (and as the literature has shown it), the most liquid maturity is the five-year one, in the US as in Europe (the average absolute bid-ask spreads of the five-year maturity is the lowest compared to that of the other maturities). This result is confirmed at the individual level ${ }^{10}$ (when we analyze the absolute bid-ask spreads bank by bank) and when we analyze the absolute bid-ask spreads of indexes (Panel C and Panel D).

\footnotetext{
${ }^{10}$ The results of this analysis are too large to be added to the article. However, they are available here: https://1drv.ms/x/s!Ag2o5eNTgsLzwTEYPE49q6gkBQGM?e=41rhWm
} 
In summary, our results show that our data are liquid in general. Indeed, although there are differences from one maturity to another, these latter are relatively moderate. Compared to the 5-year maturity (which we consider as the benchmark), the summary statistics of the absolute bid-ask spreads of the other maturities are not so far apart in general.

\subsubsection{Summary statistics}

In this subsection, we present the summary statistics of the data we used to perform our event studies (i.e. the MID spreads of CDS and CDX). Panel A (Panel B) of Appendix A.3 provides the summary statistics of CDS MID spreads in the US (Europe), at the aggregate level ${ }^{11}$.

In Appendix A.4, we provide the summary statistics of the two indexes' MID spreads: the Markit CDX North America Investment Grade Index (Panel A) and the Markit iTraxx Europe Investment Grade index (Panel B).

\section{Empirical Results}

In this paper, using the CDS spreads of all maturities, we examine the CDS market reaction to the disclosure of regulatory stress test results. In other words, we examine the market response by taking into account all CDS maturities available (not only the 5 -year maturity) in order to highlight possible differences in reactions depending on the maturity considered. We present the results in Tables 2 and 3 and in Figures 1 and 2.

More precisely, Table 2 presents the estimates of the CDS market response to the disclosure of EU-wide stress test results, at the level of all maturities. Panel A applies to the 2010 CEBS stress test while Panel B, C and D apply respectively to the 2011, 2014 and 2016 EBA stress tests. Figure 1 then presents graphically these different estimates, test by test and for all maturities.

\footnotetext{
${ }^{11}$ We also analyze the same summary statistics but year by year, at the level of each maturity. The corresponding tables are too large to be added to the article. However, they are available here:

https://1drv.ms/x/s!Ag2o5eNTgsLzwTDoyGVFHO7d4nGI?e=dBoOYe
} 
Table 3 provides the estimates of the CDS market response to the disclosure of US stress test results, for all CDS maturities ${ }^{12}$. Panel A applies to the 2009 Supervisory Capital Assessment Program (SCAP) while Panel B, C, D, E and F apply respectively to the 2013, 2014, 2015, 2016 and 2017 Dodd-Frank Act stress tests (DFAST). All estimates in this table are represented graphically in Figure 2.

For each panel of tables 2 and 3 (so for each stress test), we have eight different rows corresponding to the eight different estimates (according to the eight different CDS maturities) of the CDS market response to the disclosure of the corresponding stress test results. Considering each row, the first column corresponds to the CDS Maturity used to estimate the market response while the second column reports the Number of banks in the sample used to estimate the market response. This latter (CAARs) is reported in the third column. Then, to establish the statistical validity of our estimated CAARs, we use three parametric tests and two non-parametric tests. Columns (1), (2) and (3) report the results of the parametric tests (respectively the Patell test, the Boehmer-Musumeci-Poulsen test and the Kolari-Pynnonen test) while the columns (4) and (5) provide the results of the non-parametric tests (respectively the Generalized Sign test and the Generalized Rank test).

\subsection{Is the market response the same for all CDS maturities?}

We observe that, for each panel of Table 2, all CAARs (whatever the CDS maturity used) have the same sign. In other words, when we consider each EU-wide stress test, all the eight CAARs estimated have the same sign. They are either negative and significant (tests of 2010, 2014 and 2016) or positive and significant (test of 2011); the statistical significance of the CAARs in panel A (2010 CEBS test) and Panel D (2016 EBA test) being particularly strong.

When considering US SCAP and DFA stress tests (Table 3), we come to the same conclusions. Indeed, the eight CAARs estimated for each of the panels A, C, E and F have the same sign. They are either negative and significant (Panels A, C and F) or positive and significant (Panel E), whatever the maturity considered. As we can see,

\footnotetext{
${ }^{12}$ For the 2009 SCAP (Panel A), we could not estimate the market response using the 6-month and the 7-year maturities because of missing data.
} 
these four Panels show a strong statistical significance, especially the Panel A (2009 SCAP) and the Panel E (2016 DFAST). However, we observe a serious lack of statistical significance for the set of CAARs of the 2013 (Panel B) and the 2015 (Panel D) DFA stress tests. That's why we do not consider them.

In view of the foregoing, we argue that the nature of the CDS market response to the release of a regulatory stress test results is the same from one maturity to another. More precisely, for a given stress test, the CDS market will not react positively on one maturity (significant negative CAARs) and negatively on another one (significant positive CAARs). According to our empirical results, the nature of the reaction (positive or negative) is the same for all CDS maturities.

However, if the nature of the CDS market reaction is the same for the different maturities, is the extent of the reaction also the same from one maturity to another?

Our empirical investigations suggest that this is not the case. For a given stress test, even if the nature of the response following the results' disclosure is the same for all CDS maturities, the extent of the reaction clearly differs from one maturity to another in most cases. Indeed, for each panel presented in Table 2 (European stress tests), we observe that the different CAARs have the same sign but their values differ substantially from one maturity to another. Likewise when we consider the different US stress tests (Panels A, C, E and F of Table 3), our results show that the CAARs vary substantially from one maturity to another, at the exception of the 2009 US SCAP ${ }^{13}$.

This is the evidence that the impact of the disclosure (of a stress test results on tested banks' CDS spreads) varies significantly from one maturity to another since the CAARs estimated using different CDS maturities differ substantially. Our results therefore suggest that following the disclosure of a given stress test results, with the new relevant information provided, the CDS market reacts (responds) differently

\footnotetext{
${ }^{13}$ Our results highlight a unique and singular situation concerning the CDS market reaction following the US SCAP results' disclosure (which was the first disclosure of a regulatory stress testing exercise results in the world). Indeed, we observe that the different CAARs (Panel A) are very close to each other. In other words, participating banks experience on aggregate very significant and negative abnormal CDS returns at the level of all maturities, but there are almost no differences between these abnormal returns. By cons, for each of the 2014, 2016 and 2017 DFA stress tests, our results (reported respectively in the Panels C, E and F of Table 3) show that the CAARs vary substantially from one maturity to another; what goes in the same direction as the results that we obtained by analyzing European tests (Table 2).
} 
depending on the maturity considered. It may react strongly on one maturity (very high CAARs in absolute value) and weakly on another one (very low CAARs in absolute value). What constrains us to ask this question:

\subsection{What maturity best reflects the market response?}

A deeper analysis shows that the CDS market seems to react more strongly on shortterm maturities (from $6 \mathrm{M}$ to $3 \mathrm{Y}$ ) than on $5 \mathrm{Y}$ maturity or more, whatever the nature of the reaction. Indeed, for a given stress test, the CAARs (in absolute value) is often higher on short-term maturities than on $5 \mathrm{Y}$ maturity or more. And going deeper, we observe that in most cases, the lower the maturity of the CDS, the stronger the market reaction i.e. the higher the CAARs in absolute value ${ }^{14}$. This is the case when we consider the 2014 and 2016 US DFA stress tests, and all European stress tests except the 2014 one.

For the remaining tests (the 2014 EU-wide stress test and the 2017 US DFA stress test), the CDS market also reacts differently depending on the maturity considered since the CAARs differ from one maturity to another. But in these cases (especially the $2014 \mathrm{EU}-$ wide stress test), the reaction is weaker on short-term maturities compared to the 5year maturity.

According to our results, we argue that 5-year CDS maturity may not be the suitable maturity to measure the CDS market reaction to stress test results' disclosure. Shorter maturities (6-month, 1-year, 2-year and 3-year) should better reflect the market response. Indeed, short-term maturities of CDS should be more relevant to assess the market response since the forward-looking stressed scenarios of a stress testing exercise have a time horizon of 3 years, and since the disclosed results only cover these 3 years.

\footnotetext{
${ }^{14}$ Graphically, this results by an ascending curve below the x-axis (in case of downward corrections) or a downward curve above the $\mathrm{x}$-axis (in case of upward corrections).
} 


\subsection{Difference between several stress tests in term of the relevance of the information revealed.}

Our results also show that using shorter maturities enables to better judge the difference between several tests in term of market response (so in term of the revealed information's relevance and novelty). Indeed, for a given maturity, the larger the difference between the CAARs of two stress tests, the greater the difference between these latter in terms of the revealed information's relevance. According to our results, the difference between the CAARs of two distinct stress tests differs (considerably most of times) from one maturity to another in Europe as in the US. In other words, by comparing two distinct stress tests in term of market response (so in term of the revealed information's relevance and novelty), the results that we obtained are not the same from one maturity to another.

The most striking example concerns the 2014 and 2017 US stress tests. By analyzing these latter basing only on the 5Y maturity, one would conclude that there is almost no difference between them. In other words, the market response to both tests is almost the same. But, looking at the shorter maturities $(6 \mathrm{M}, 1 \mathrm{Y}, 2 \mathrm{Y}, 3 \mathrm{Y}$ and $4 \mathrm{Y})$, we can see that this is no longer the case. While the difference between the two tests' CAARs is $0,37 \%$ with the $5 \mathrm{Y}$ maturity, we find a difference of $9,77 \%$ with the $6 \mathrm{M}$ maturity. And considering the other maturities (1Y, $2 Y, 3 Y, 4 Y)$, we observe that the lower the maturity of the CDS, the higher the difference. Our results therefore suggest that the difference between several stress tests in term of the revealed information's relevance and market response is not the same from one maturity to another. More accurately, this difference is higher on short-term maturities comparing to $5 \mathrm{Y}$ maturity or more and in most cases, the lower the maturity of the CDS, the higher the difference. What leads us to argue that short-term CDS maturities allow to better discriminate stress tests according to their revealed information's relevance and novelty, comparing to $5 \mathrm{Y}$ maturity or more and the lower the maturity, the better the discrimination is.

According to us, it is a confirmation of our previous findings, namely $5 \mathrm{Y}$ maturity may not be the suitable maturity to measure the informative value of a stress test; shortterm maturities are more suitable. 


\subsection{Robustness checks}

This section reports several robustness tests relating to the estimation window (used to estimate the market model parameters) and the event window.

\subsubsection{Alternative estimation windows}

To assess the robustness of our findings, we first consider two alternative estimation windows (in place of the 120-trading days window used). More precisely, we consider a shorter estimation window of 84-trading days (following Covi and Ambrosini, 2016) and a longer estimation window of 200-trading days.

Overall, the results from these two alternative estimation windows ${ }^{15}$ are very similar to that of the 120-trading days window (almost the same), thus strongly confirming our findings and conclusions.

\subsubsection{Alternative event windows}

To check the robustness of our findings, we also consider four alternatives regarding the event windows: $[-2,+2] ;[-3,+3] ;[0,+1]$ and $[0,+3]$. The results obtained ${ }^{16}$ are in line with our main findings.

In sum, the robustness tests show that our main results remain unchanged and are confirmed.

\section{Discussion of results and Recommendations}

Our empirical findings offer a number of interesting implications that we discuss in what follows.

According to our results, the nature of the CDS market reaction following the disclosure is the same for all CDS maturities: either a positive reaction (significant

\footnotetext{
15 The estimation of the market response when we employ these two alternative estimation windows are available here: https://1drv.ms/x/s!Ag2o5eNTgsLzwTI4TvrN6HgHewDK?e=7zt868

${ }^{16}$ The estimation of the market response when we employ these four alternative event windows are available here: https://1drv.ms/x/s!Ag2o5eNTgsLzwS8E5X1SVkp8MmpC?e=QjjZxy
} 
negative CAARs), or a negative reaction (significant positive CAARs) for all maturities. This finding indicates that the CDS market overvalues or undervalues the default risk of tested banks, whether in the short-term or in the medium-term. Hence, following the disclosure, with the new, relevant and useful information provided, the CDS market reassesses the default risk of participating banks and adjusts accordingly their corresponding spreads of CDS, at the level of all maturities. This adjustment can take the form of an upward correction (i.e. an increase in the CDS spread) in case of undervaluation of default risk, or a downward correction (i.e. a decrease in the CDS spread) in case of overvaluation of default risk. But according to our results, for a given stress test, the nature of the correction is the same for all CDS maturities: either an upward correction, or a downward correction for all maturities.

Then, going deeper, we find that even if the nature of the correction is the same for all CDS maturities, the extent of the correction differs from one maturity to another. In other words, for a given stress test, the CDS market corrects (adjusts) differently the spreads of CDS of tested banks depending on the maturity considered. This allows us to argue that the extent of the overvaluation (undervaluation) of tested banks' default risk is not the same from one maturity to another (through time). More precisely, we evidence that the overvaluation (undervaluation) of default risk is often more marked in the short-term than at 5-year or more and in most cases, the lower the maturity of the CDS, the higher the extent of the overvaluation (undervaluation). This shows that information contents provided by the disclosure of stress test results are not the same trough time.

Since the spreads of a banking institution's CDS reflect the market perceptions of its solvency and financial health (among others), the publication of stress test results necessarily has an impact on these spreads and as Ellahie (2013), Morgan et al. (2014), Neretina et al. (2014) and Flannery et al. (2015), we proved it. To measure this impact and the informative value of the stress test, the literature almost systematically uses the maturity of 5-year. But in view of our findings (supported by empirical evidence), we argue that it may not be the suitable maturity to perform this measure. More precisely, the only use of the 5-year maturity in the examination of a regulatory stress test effects is not suitable. Short-term CDS maturities matter (6-month, 1-year, 2-year 
and 3-year maturities).

Analyzing the CDS market response to the disclosure using these short-term maturities firstly allows to better appreciate this response. As we show above, they should better reflect the market response. Secondly, short-term CDS maturities allow to better judge the difference between several stress tests according to their revealed information's relevance and novelty (so according to the tests' quality). Thirdly, we might argue that analyzing the CDS market response using shorter maturities than 5year will better reflect the assessment by the market of participating banks' financial health and solvency.

Consequently, to analyze the impact and the informative value of a stress testing exercise on CDS market, we recommend to use not only the 5-year CDS maturity, but also the shorter maturities (6-month, 1-year, 2-year and 3-year maturities).

\section{Conclusion}

In this paper, we were interested to know if the only use of the 5-year maturity CDS spreads in the examination of the CDS market response to regulatory stress tests is suitable. Therefore, we investigate whether the short-term maturities of CDS provide the same information as the $5 \mathrm{Y}$ maturity.

To conduct our investigations and find an answer to our questions, we consider the ten regulatory banking stress tests that were performed in Europe and in the US, in the time period from 2009 to 2017. Then, we examine whether the CDS market reaction is the same from one maturity to another. We therefore apply, for each stress test, an event study methodology on tested banks' daily CDS spread returns considering each of the eight different maturities (6-month, 1Y, 2Y, 3Y, 4Y, 5Y, 7Y and 10Y maturities).

We evidence that for a given stress test, the nature of the CDS market response following the disclosure of stress test results is the same whatever the maturity considered: either a positive reaction, or a negative reaction for all maturities. However, even if the nature of the CDS market response is the same for all CDS maturities, its importance (extent) differs considerably from one maturity to another. 
More accurately, we evidence that in most cases, the lower the maturity of the CDS, the stronger the market reaction i.e. the higher the CAARs in absolute value. Consequently, we firstly argue that the only use of the 5-year maturity in the examination of a regulatory stress test effects is not suitable. Short-term maturities of CDS (6-month, 1-year, 2-year and 3-year) matter since they should better reflect the market response. Secondly, we argue that short-term CDS maturities allow to better discriminate stress tests according to their revealed information's relevance and the lower the maturity, the better the discrimination is. Finally, our findings suggest that the CDS market overvalues or undervalues the default risk of tested banks, whether in the short term or in the medium term. Further analysis shows that the extent of this overvaluation (undervaluation) is not the same from one maturity to another. In most cases, the lower the maturity of the CDS, the higher the extent of the overvaluation (undervaluation). 


\section{References}

Ahern K., 2009, "Sample selection and event study estimation", Journal of Empirical Finance, Volume 16, Issue 3, June 2009, Pages 466-482.

Ahnert L., Vogt P., Vonhoff V. and Weigert F., 2018, "The Impact of Regulatory Stress Testing on Bank's Equity and CDS Performance", University of St.Gallen - School of Finance Research Paper No. 2018/15, May 2018.

Alves C., Mendes V. and Da Silva P., 2015, "Do stress tests matter? A study on the impact of the disclosure of stress test results on European financial stocks and CDS markets", Applied Economics, Volume 47, Issue 12, January 2015, Pages 1213-1229.

Annaert J., De Ceuster M., Van Roy P. and Vespro C., 2013, "What determines Euro area bank CDS spreads", Journal of International Money and Finance, Volume 32, February 2013, Pages 444-461.

Arakelyan A. and Serrano P., 2016, "Liquidity in Credit Default Swap Markets", Journal of Multinational Financial Management, Volumes 37-38, December 2016, Pages 139-157.

Barrucci E., Baviera R. and Milani C., 2014, "Is the comprehensive assessment really comprehensive?", SSRN Electronic Journal, December 2014, DOI: 10.2139/ssrn.2541043.

Berger A., Davies S. and Flannery M., 2000, “Comparing Market and Supervisory Assessments of Bank Performance: Who Knows What When?", Journal of Money, Credit and Banking, Volume 32, Issue 3, August 2000, Pages 641-667.

Boehmer E., Musumeci J. and Poulsen A., 1991, "Event-study methodology under conditions of event-induced variance", Journal of Financial Economics, Volume 30, Issue 2, December 1991, Pages 253-272.

Bongaerts D., De Jong F. and Driessen J., 2011, "Derivative pricing with liquidity risk: theory and evidence from credti default swap market", The Journal of Finance, Volume 66, Issue 1, February 2011, Pages 203-240. 
Breckenfelder J. and Schwaab B., 2015, “Bank to sovereign risk spillovers across borders: Evidence from the ECB's comprehensive assessment", Journal of Empirical Finance, Volume 49, December 2018, Pages 247-262.

Brown J. and Warner J., 1985, "Using daily stock returns: The case of event studies", Journal of Financial Economics, Volume 14, Issue 1, March 1985, Pages 3-31.

Brown S. and Warner J., 1980, "Measuring security price performance", Journal of Financial Economics, Volume 8, Issue 3, September 1980, Pages 205-258.

Campbell J. Y., Lo A. and MacKinlay A., 1997, “The Econometrics of Financial Markets", Princeton University Press. JSTOR, www.jstor.org/stable/j.ctt7skm5

Campbell J.C., Cowan A. and Salotti V., 2010, "Multi-country event-study methods", Journal of Banking \& Finance, Volume 34, Issue 12, December 2010, Pages 3078-3090.

Candelon B. and Sy A., 2015, “How did Markets React to Stress Tests?” IMF Working Paper WP/15/75, April 2015.

Coro F., Dufour A. and Varotto S., 2012, "The time varying properties of credit and liquidity components of CDS spreads", SSRN Electronic Journal, August 2012, DOI: 10.2139/ssrn.2011092

Covi G. and Ambrosini G., 2016, "Stressing Bank's Asset Variance: The Impact of the 2014 Comprehensive Assessment on the CDS-Stock Relationship", SSRN Electronic Journal, February 2016, DOI: 10.2139/ssrn.2735169.

Corrado C. and Zivney T., 1992, “The specification and power of the sign test in event study hypothesis tests using daily stock returns", The Journal of Financial and Quantitative Analysis, Volume 27, Issue 3, September 1992, Pages 465-478.

Corrado C., 1989, “A nonparametric test for abnormal security price performance in event studies", Journal of Financial Economics, Volume 23, Issue 2, August 1989, Pages 385-395.

Cowan A., 1992, "Nonparametric event study tests", Review of Quantitative Finance and Accounting, December 1992, Volume 2, Issue 4, Pages 343-358. 
Cowan A., 2017, "Goodbye to the Patell Test in Eventus", November 2017. https://www.researchgate.net/publication/321304366 Goodbye to the Patell Test in Eventus

Ellahie A., 2013, "Capital Market Consequences of EU Bank Stress Tests", SSRN Electronic Journal, May 2013, DOI: 10.2139/ssrn.2157715.

Flannery M., Hirtle B. and Kovner A., 2017, “Evaluating the Information in the Federal Reserve Stress Tests", Journal of Financial Intermediation, Volume 29, January 2017, Pages 1-18.

Flannery M., Kwan S. and Nimalendran M., 2010, “The 2007-09 Financial Crisis and Bank Opaqueness", Federal Reserve Bank of San Francisco, Working Paper Series. DOI: $10.24148 / w p 2010-27$.

Georgescu O.-M., Gross M., Kapp D. and Kok C., 2017, "Do stress tests matter? Evidence from the 2014 and 2016 stress tests", ECB Working Paper N²054, May 2017.

Graham A., Pirie W. and Powell W., 1996, "Detecting abnormal returns using the market model with pre-tested data", Journal of Financial Research, Volume 19, Issue 1, Pages 21-40.

Harrington S. and Shrider D., 2007, “All events induce variance: Analyzing abnormal returns when effects vary across firms", Journal of Financial and Quantitative Analysis, Volume 42, Issue 1, March 2007, Pages 229-256.

Higgins E. and Peterson D., 1998, “The power of one and two sample t-statistics given event-induced variance increases and nonnormal stock returns: A comparative study", Quarterly Journal of Business and Economics, Volume 37, Issue 1, Winter 1998, Pages 27-49.

Kaspereit T., 2018, “eventstudy2 - A program to perform event studies with complex test statistics in Stata (Version 2.0.2)".

Kolari J. and Pynnönen S., 2010, “Event Study Testing with Cross-sectional Correlation of Abnormal Returns", The Review of Financial Studies, Volume 23, Issue 11, November 2010, Pages 3996-4025. 
Kolari J. and Pynnönen S., 2011, “Nonparametric rank tests for event studies”, Journal of Empirical Finance, Volume 18, Issue 5, December 2011, Pages 953-971.

Krivin D., Patton R., Rose E. and Tabak D., 2003, “Determination of the Appropriate Event Window Length in Individual Stock Event Studies", NERA Economic Consulting, November 2003. DOI: 10.2139/ssrn.466161.

MacKinlay A., 1997, "Event studies in economics and finance", Journal of Economic Literature, Volume 35, Issue 1, March 1997, Pages 13-39.

Marks J. and Musumeci J., 2017, “Misspecification in event studies", Journal of Corporate Finance, Volume 45, August 2017, Pages 333-341.

Morgan D., 2002, "Rating banks: risk and uncertainty in an opaque industry", The American Economic Review, Volume 92, Issue 4, September 2002, pages 874-888.

Morgan D., Peristiani S. and Savino V., 2014, “The Information Value of the Stress Test”. Journal of Money, Credit and Banking, Volume 46, Issue 7, October 2014, pages 1479-1500.

Neretina E., Sahin C. and De Haan J., 2014, "Bank stress test effects on returns and risks", De Nederlandsche Bank Working Paper N 419, April 2014.

Patell J., 1976, “Corporate forecasts of earnings per share and stock price behavior: Empirical tests", Journal of Accounting Research, Volume 14, Issue 2, Autumn 1976, Pages 246-276.

Petrella G. and Resti A., 2013, “Supervisors as information producers: Do stress tests reduce bank opaqueness?" Journal of Banking \& Finance, Volume 37, Issue 12, December 2013, Pages 5406-5420.

Pires P., Perreira J.-P. and Martins L., 2011, "The complete picture of credit default swap spreads - a quantile regression approach", ISCTE Business School Working Paper, January 2011.

Samaniego-Medina R., Trujillo-Ponce A., Parrado-Martínez P. and Di Pietro F., 2016, "Determinants of bank CDS spreads in Europe" Journal of Economics and Business, Volume 86, July-August 2016, Pages 1-15. 
Tang D. and Yan H., 2007, "Liquidity and Credit Default Swap Spreads", SSRN Electronic Journal, September 2007, DOI: 10.2139/ssrn.891263.

Tang D. and Yan H., 2010, "Market conditions, default risk and credit spreads", Journal of Banking \& Finance, Volume 34, Issue 4, April 2010, Pages 743-753.

Tang D. and Yan H., 2013, "What Moves CDS Spreads?", SSRN Electronic Journal, June 2013, DOI: 10.2139/ssrn.1786354.

Völz M. and Wedow M., 2011, "Market discipline and too-big-to fail in the CDS market: Does banks' size reduce market discipline?", Journal of Empirical Finance, Volume 18, Issue 2, March 2011, Pages 195-210. 
Table 1: The results' disclosure date and the corresponding event date in the US and in Europe.

Panel A: Timeline of regulatory stress test disclosures in the US (2009-2017)

\begin{tabular}{lll}
\hline Stress Test & Release Date & Event Date \\
\hline 2009 SCAP & Thursday May 7, 2009 & Friday May 8, 2009 \\
2013 DFA Stress Test & Thursday March 7, 2013 & Friday March 8, 2013 \\
2014 DFA Stress Test & Thursday March 20, 2014 & Friday March 21, 2014 \\
2015 DFA Stress Test & Thursday March 5, 2015 & Friday March 6, 2015 \\
2016 DFA Stress Test & Thursday June 23, 2016 & Friday June 24, 2016 \\
2017 DFA Stress Test & Thursday June 22, 2017 & Friday June 23, 2017 \\
\hline
\end{tabular}

Panel B: Timeline of regulatory stress test disclosures in Europe (2009-2017)

\begin{tabular}{lll}
\hline Stress Test & Release Date & Event Date \\
\hline 2010 EU-wide Stress Test & Friday, 23 July 2010 & Monday, 26 July 2010 \\
2011 EU-wide Stress Test & Friday, 15th July 2011 & Monday, 18 July 2011 \\
2014 EU-wide Stress Test & Sunday, 26 October 2014 & Monday, 27 October 2014 \\
2016 EU-wide Stress Test & Friday, 29 July 2016 & Monday, 01 August 2016 \\
\hline
\end{tabular}


Table 2: The impact on CDS market of the disclosure of European stress tests' results.

\begin{tabular}{|c|c|c|c|c|c|c|c|}
\hline Maturity & $\begin{array}{l}\text { Number } \\
\text { of banks }\end{array}$ & CAARs & $\begin{array}{c}\text { Patell } \\
\text { p-value } \\
(1)\end{array}$ & $\begin{array}{c}\text { BMP } \\
\text { p-value } \\
(2) \\
\end{array}$ & $\begin{array}{c}\text { KP } \\
\text { p-value } \\
(3)\end{array}$ & $\begin{array}{c}\text { GenSign } \\
\text { p-value } \\
(4)\end{array}$ & $\begin{array}{c}\text { GRANK } \\
\text { p-value } \\
\text { (5) }\end{array}$ \\
\hline \multicolumn{8}{|c|}{ Panel A: The 2010 CEBS Stress test } \\
\hline 0,5 & 41 & $-10,38 \%$ & *** & $* * *$ & $* * *$ & $* * *$ & $* *$ \\
\hline 1 & 40 & $-10,46 \%$ & $* * *$ & $* * *$ & $* *$ & $* * *$ & $* *$ \\
\hline 2 & 39 & $-9,17 \%$ & $* * *$ & $* * *$ & $* *$ & $* * *$ & $* *$ \\
\hline 3 & 41 & $-7,88 \%$ & *** & *** & ** & $* * *$ & ** \\
\hline 4 & 38 & $-6,88 \%$ & *** & *** & & *** & ** \\
\hline 5 & 41 & $-7,00 \%$ & $* * *$ & $* * *$ & & $* * *$ & * \\
\hline 7 & 39 & $-7,74 \%$ & $* * *$ & $* * *$ & * & $* * *$ & ** \\
\hline 10 & 41 & $-8,11 \%$ & $* * *$ & *** & * & *** & ** \\
\hline
\end{tabular}

\begin{tabular}{rrrrll}
\hline \multicolumn{7}{c}{ Panel B: The 2011 EBA Stress test } & & $* *$ \\
\hline 0,5 & 39 & $2,49 \%$ & $* * *$ & $* * *$ & $* *$ \\
1 & 38 & $2,63 \%$ & $* * *$ & $* * *$ & $* *$ \\
2 & 37 & $2,48 \%$ & $* * *$ & $* * *$ & $*$ \\
3 & 39 & $2,16 \%$ & $* * *$ & $* * *$ & $*$ \\
4 & 36 & $2,46 \%$ & $* * *$ & $* * *$ & $* *$ \\
5 & 39 & $2,13 \%$ & $* * *$ & $* * *$ & $*$ \\
7 & 37 & $1,90 \%$ & $* * *$ & $* * *$ & \\
10 & 39 & $1,59 \%$ & $* * *$ & $* * *$ & $*$ \\
\hline
\end{tabular}

\begin{tabular}{|c|c|c|c|c|c|}
\hline 0,5 & 49 & $-0,03 \%$ & ** & ** & ** \\
\hline 1 & 47 & $-0,57 \%$ & $* *$ & $* *$ & $* *$ \\
\hline 2 & 48 & $-0,59 \%$ & $* * *$ & ** & \\
\hline 3 & 50 & $-1,38 \%$ & $* * *$ & $* *$ & * \\
\hline 4 & 48 & $-2,62 \%$ & $* * *$ & $* * *$ & $* *$ \\
\hline 5 & 50 & $-3,42 \%$ & $* * *$ & $* * *$ & $* * *$ \\
\hline 7 & 48 & $-1,35 \%$ & $* * *$ & $* * *$ & \\
\hline 10 & 50 & $-3,21 \%$ & $* * *$ & $* * *$ & $* * *$ \\
\hline
\end{tabular}

\begin{tabular}{|c|c|c|c|c|c|c|c|}
\hline \multicolumn{8}{|c|}{ Panel D: The 2016 EBA Stress test } \\
\hline 0,5 & 33 & $-4,82 \%$ & $* * *$ & $* * *$ & * & $* * *$ & * \\
\hline 1 & 33 & $-4,51 \%$ & *** & *** & * & $* * *$ & \\
\hline 2 & 33 & $-3,59 \%$ & *** & *** & * & $* * *$ & \\
\hline 3 & 33 & $-3,36 \%$ & *** & $* * *$ & * & $* * *$ & \\
\hline 4 & 33 & $-2,67 \%$ & *** & *** & & $* * *$ & \\
\hline 5 & 33 & $-2,76 \%$ & *** & *** & * & $* * *$ & \\
\hline 7 & 33 & $-2,04 \%$ & *** & *** & & *** & \\
\hline 10 & 33 & $-2,24 \%$ & *** & $* * *$ & * & $* * *$ & \\
\hline
\end{tabular}

Source: Authors' calculation.

Notes: This Table presents the estimates of the CDS market response to the disclosure of EU-wide stress test results, in the time period from 2009 to 2017 and at the level of all CDS maturities. Panel A applies to the 2010 CEBS stress test while Panel B, C and D apply respectively to the 2011, 2014 and 2016 EBA stress tests. For each panel (so for each stress test), we have eight different rows corresponding to the eight different estimates (according to the eight different CDS maturities) of the CDS market response 
to the disclosure of the corresponding stress test results. Considering each row, the first column corresponds to the CDS Maturity used to estimate the market response while the second column reports the Number of banks in the sample used to estimate the market response. This latter (CAARs) is reported in the third column. CAARs indeed refers to the Cumulative Average Abnormal (CDS) Returns computed employing an event study methodology (on a three-day event window including the event date and the two following days $(t, t+1, t+2)$, with a 120-trading day estimation window covering the period $[\mathrm{t}-130 ; \mathrm{t}-11])$. To establish its statistical validity, we use three parametric tests and two nonparametric tests. The columns (1), (2) and (3) report the results of the parametric tests (respectively the Patell test, the Boehmer-Musumeci-Poulsen test and the Kolari-Pynnonen test) while the columns (4) and (5) provide the results of the non-parametric tests (respectively the Generalized Sign test and the Generalized Rank test). ${ }^{*}, * * * * *$ indicate statistical significance respectively at $10 \%, 5 \%$ and $1 \%$ levels. 
Table 3: The impact on CDS market of the disclosure of US stress tests' results.

\begin{tabular}{rrrrcccc}
\hline Maturity & $\begin{array}{c}\text { Number } \\
\text { of banks }\end{array}$ & CAARs & $\begin{array}{c}\text { Patell } \\
\text { p-value } \\
(1)\end{array}$ & $\begin{array}{c}\text { BMP } \\
\text { p-value } \\
(2)\end{array}$ & $\begin{array}{c}\text { KP } \\
\text {-value } \\
(3)\end{array}$ & $\begin{array}{c}\text { GenSign } \\
\text {-value } \\
(4)\end{array}$ & $\begin{array}{c}\text { GRANK } \\
\text {-value } \\
(5)\end{array}$ \\
\hline \multicolumn{2}{l}{ Panel A: The 2009 SCAP } & & & & & - \\
\hline 0,5 & - & - & - & - & - & - & $* *$ \\
1 & 9 & $-13,41 \%$ & $* * *$ & $* * *$ & & $* *$ & $* *$ \\
2 & 9 & $-13,46 \%$ & $* * *$ & $* * *$ & $*$ & $* *$ & $* * *$ \\
3 & 9 & $-13,21 \%$ & $* * *$ & $* * *$ & $* *$ & $* * *$ & $* * *$ \\
4 & 9 & $-13,51 \%$ & $* * *$ & $* * *$ & $* * *$ & $* * *$ & $* *$ \\
5 & 9 & $-12,97 \%$ & $* * *$ & $* * *$ & $*$ & $* * *$ & $* *$ \\
7 & - & - & - & - & - & - & - \\
10 & 9 & $-16,49 \%$ & $* * *$ & $* * *$ & $* * *$ & $* * *$ & $* * *$ \\
\hline
\end{tabular}

Panel B: The 2013 DFA Stress test

\begin{tabular}{|c|c|c|c|c|c|c|c|}
\hline 0,5 & 11 & $-0,10 \%$ & & & & & \\
\hline 1 & 11 & $3,31 \%$ & & & & \multirow[b]{2}{*}{ ** } & \\
\hline 2 & 11 & $2,32 \%$ & & & & & \\
\hline 3 & 11 & $1,81 \%$ & & & & \multirow{5}{*}{$* *$} & \\
\hline 4 & 11 & $0,21 \%$ & & & & & \\
\hline 5 & 11 & $0,63 \%$ & & & & & \\
\hline 7 & 11 & $0,11 \%$ & & & & & \\
\hline 10 & 11 & $0,08 \%$ & & 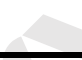 & & & \\
\hline \multicolumn{8}{|c|}{ Panel C: The 2014 DFA Stress test } \\
\hline 0,5 & 11 & $-11,72 \%$ & $* *$ & $* * *$ & \multirow{8}{*}{ * } & \multirow[t]{3}{*}{$* *$} & * \\
\hline 1 & 11 & $-10,01 \%$ & $* * *$ & $* * *$ & & & \\
\hline 2 & 11 & $-6,22 \%$ & $* * *$ & $* * *$ & & & * \\
\hline 3 & 11 & $-4,87 \%$ & $* * *$ & $* * *$ & & *** & ** \\
\hline 4 & 11 & $-3,19 \%$ & ** & $* * *$ & & $* * *$ & \\
\hline 5 & 11 & $-3,05 \%$ & *** & *** & & $* * *$ & \\
\hline 7 & 11 & $-1,47 \%$ & & & & & \\
\hline 10 & 11 & $-1,04 \%$ & & & & ** & \\
\hline \multicolumn{8}{|c|}{ Panel D: The 2015 DFA Stress test } \\
\hline 0,5 & 11 & $4,48 \%$ & & * & & * & * \\
\hline 1 & 11 & $-0,60 \%$ & & & & & \\
\hline 2 & 11 & $1,84 \%$ & & & & & \\
\hline 3 & 11 & $0,54 \%$ & & & & & \\
\hline 4 & 11 & $1,02 \%$ & & & & & \\
\hline 5 & 11 & $0,97 \%$ & & & & ** & \\
\hline 7 & 11 & $1,67 \%$ & & & & * & \\
\hline 10 & 11 & $1,16 \%$ & & & & & \\
\hline
\end{tabular}

Panel E: The 2016 DFA Stress test

$\begin{array}{rrrrllll}0,5 & 11 & 18,43 \% & * * * & * * * & * * * & * * * & * * \\ 1 & 11 & 14,49 \% & * * * & * * * & * * * & * * * & * * \\ 2 & 11 & 13,98 \% & * * * & * * * & * * * & * * * & * * \\ 3 & 11 & 14,02 \% & * * * & * * * & * * * & * * * & * * \\ 4 & 11 & 12,15 \% & * * * & * * * & * * * & * * * & * * *\end{array}$




\begin{tabular}{|c|c|c|c|c|c|c|c|}
\hline 5 & 11 & $10,38 \%$ & $* * *$ & *** & ** & $* * *$ & ** \\
\hline 7 & 11 & $9,05 \%$ & $* * *$ & $* * *$ & *** & *** & ** \\
\hline 10 & 11 & $9,67 \%$ & *** & *** & *** & *** & *** \\
\hline \multicolumn{8}{|c|}{ Panel F: The 2017 DFA Stress test } \\
\hline 0,5 & 12 & $-1,95 \%$ & ** & & & & \\
\hline 1 & 12 & $-2,62 \%$ & ** & & & & \\
\hline 2 & 12 & $-3,24 \%$ & $* * *$ & * & & * & \\
\hline 3 & 12 & $-3,36 \%$ & *** & $*$ & & * & \\
\hline 4 & 12 & $-3,80 \%$ & *** & *** & & *** & ** \\
\hline 5 & 12 & $-2,69 \%$ & $* * *$ & $* *$ & & $* * *$ & \\
\hline 7 & 12 & $-3,80 \%$ & $* * *$ & $* * *$ & & ** & \\
\hline 10 & 12 & $-3,93 \%$ & $* * *$ & $* * *$ & & $*$ & \\
\hline
\end{tabular}

Source: Authors' calculation.

Notes: This Table presents the estimates of the CDS market response to the disclosure of US stress test results, in the time period from 2009 to 2017 and at the level of all CDS maturities. Panel A applies to the 2009 Supervisory Capital Assessment Program (SCAP) while Panel B, C, D, E and F apply respectively to the 2013, 2014, 2015, 2016 and 2017 Dodd-Frank Act stress tests (DFAST). For each panel (so for each stress test), we have eight different rows corresponding to the eight different estimates (according to the eight different CDS maturities) of the CDS market response to the disclosure of the corresponding stress test results. Considering each row, the first column corresponds to the CDS Maturity used to estimate the market response while the second column reports the Number of banks in the sample used to estimate the market response. This latter (CAARs) is reported in the third column. CAARs indeed refers to the Cumulative Average Abnormal (CDS) Returns computed employing an event study methodology (on a three-day event window including the event date and the two following days $(t, t+1, t+2)$, with a 120-trading day estimation window covering the period [t-130; $t-11])$. To establish its statistical validity, we use three parametric tests and two non-parametric tests. The columns (1), (2) and (3) report the results of the parametric tests (respectively the Patell test, the Boehmer-MusumeciPoulsen test and the Kolari-Pynnonen test) while the columns (4) and (5) provide the results of the nonparametric tests (respectively the Generalized Sign test and the Generalized Rank test). ${ }^{*}, * *{ }^{* * *}$ indicate statistical significance respectively at $10 \%, 5 \%$ and $1 \%$ levels. 
Figure 1: The impact of the disclosure of European stress tests' results 


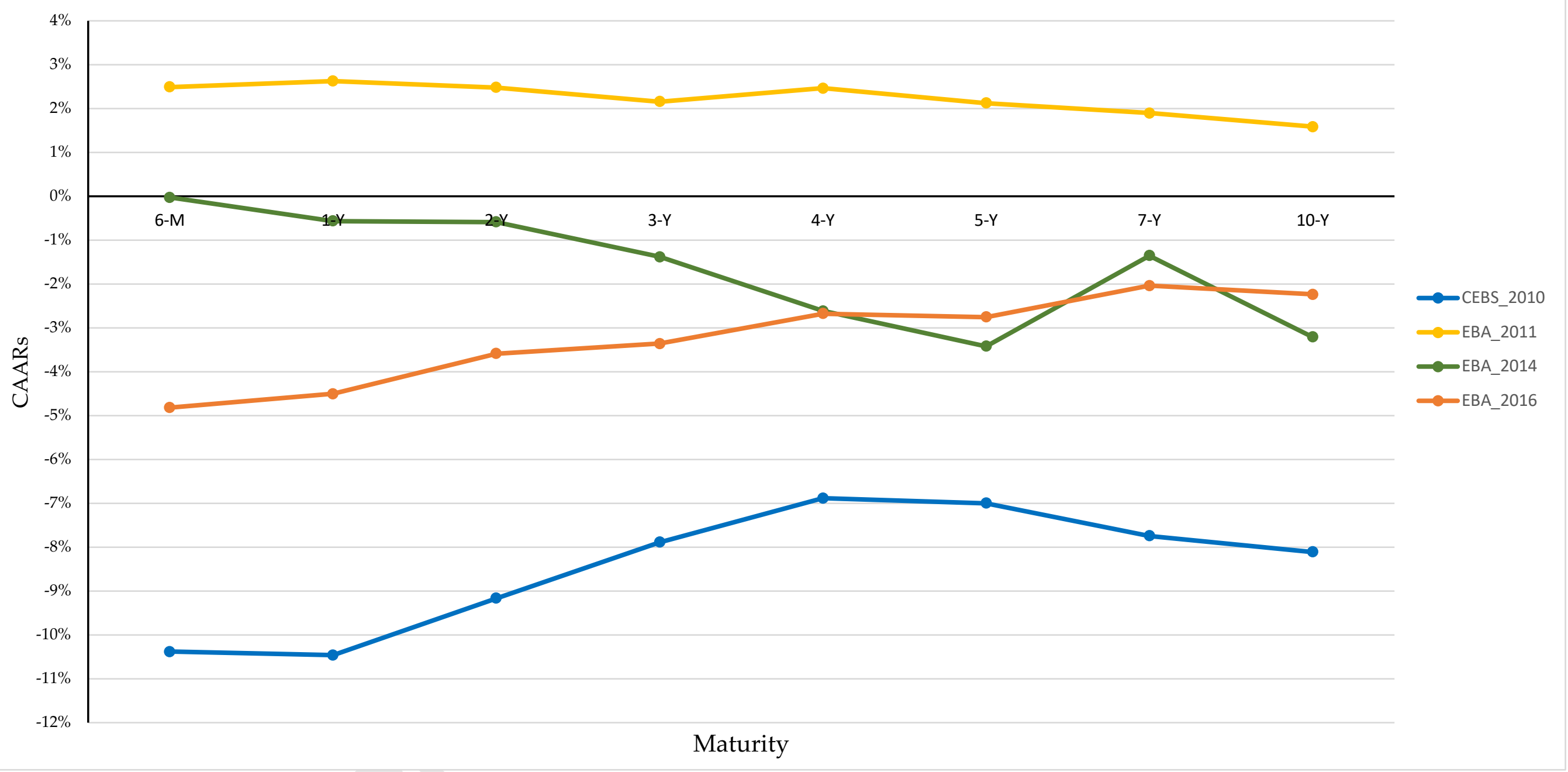

Figure 2: The impact of the disclosure of US stress tests' results. 


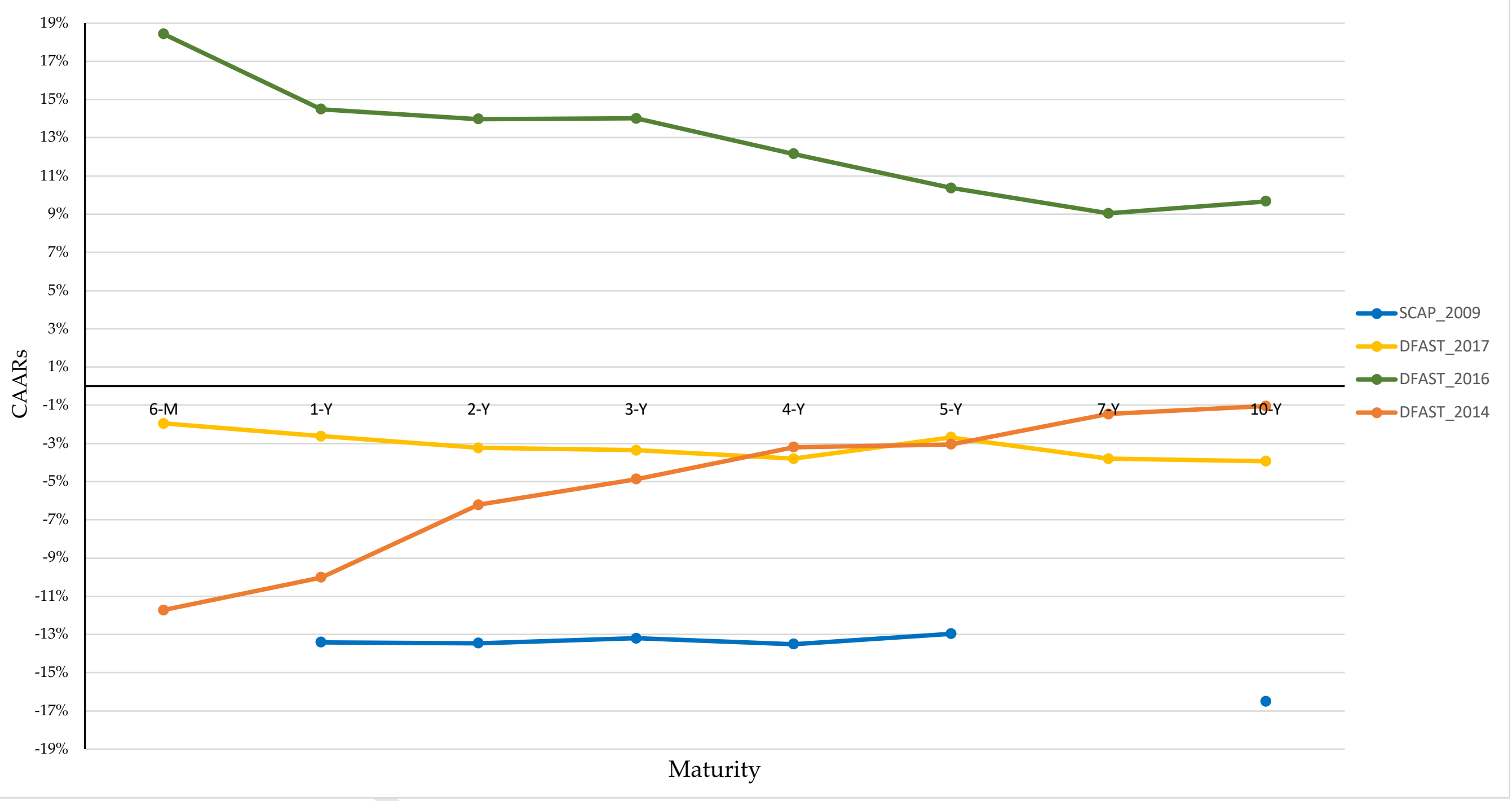


Appendix A.1: List of tested banks included in our final sample, test by test.

Considering a given stress test column, $\times$ indicates tested banks with available data on tradable credit default swap (so banks with available CDS spread returns). Hence, it indicates banks that we consider to examine the impacts of the test.

Panel A: List of banks included in our final US sample

\begin{tabular}{|l|c|c|c|c|c|c|c|}
\hline \multicolumn{1}{|c|}{ Bank Name } & $\begin{array}{c}\text { Bank } \\
\text { Country }\end{array}$ & $\begin{array}{c}\mathbf{2 0 0 9} \\
\text { SCAP }\end{array}$ & $\begin{array}{c}\mathbf{2 0 1 3} \\
\text { DFA test }\end{array}$ & $\begin{array}{c}\mathbf{2 0 1 4} \\
\text { DFA test }\end{array}$ & $\begin{array}{c}2015 \\
\text { DFA test }\end{array}$ & $\begin{array}{c}\mathbf{2 0 1 6} \\
\text { DFA test }\end{array}$ & $\begin{array}{c}2017 \\
\text { DFA test }\end{array}$ \\
\hline Ally Financial Inc & U.S. & $\times$ & $\times$ & $\times$ & $\times$ & $\times$ & $\times$ \\
American Express Co & U.S. & $\times$ & $\times$ & $\times$ & $\times$ & $\times$ & $\times$ \\
Bank of America Corp & U.S. & $\times$ & $\times$ & $\times$ & $\times$ & $\times$ & $\times$ \\
Capital One Financial Corp & U.S. & $\times$ & $\times$ & $\times$ & $\times$ & $\times$ & $\times$ \\
CIT Group Inc & U.S. & & & & & & $\times$ \\
Citigroup Inc & U.S. & $\times$ & $\times$ & $\times$ & $\times$ & $\times$ & $\times$ \\
JPMorgan Chase \& Co & U.S. & $\times$ & $\times$ & $\times$ & $\times$ & $\times$ & $\times$ \\
Morgan Stanley & U.S. & $\times$ & $\times$ & $\times$ & $\times$ & $\times$ & $\times$ \\
The Goldman Sachs Group Inc & U.S. & $\times$ & $\times$ & $\times$ & $\times$ & $\times$ & $\times$ \\
The PNC Financial Services Group Inc & U.S. & & $\times$ & $\times$ & $\times$ & $\times$ & $\times$ \\
US Bancorp & U.S. & & $\times$ & $\times$ & $\times$ & $\times$ & $\times$ \\
Wells Fargo \& Co & U.S. & $\times$ & $\times$ & $\times$ & $\times$ & $\times$ & $\times$ \\
\hline
\end{tabular}

Sources: U.S. Federal Reserve (FED) and Authors' calculation.

Notes: All the above companies are banks, with the exception of the first 2 (Ally Financial Inc. and American

Express Co) which belongs to the "Diversified Financial Services" industry.

Panel B: List of tested banks included in our final European sample

\begin{tabular}{|c|c|c|c|c|c|}
\hline Bank_Name & Bank Country & $\begin{array}{c}2010 \\
\text { CEBS test }\end{array}$ & $\begin{array}{c}2011 \\
\text { EBA test }\end{array}$ & $\begin{array}{c}2014 \\
\text { EBA test }\end{array}$ & $\begin{array}{c}2016 \\
\text { EBA test }\end{array}$ \\
\hline ABN AMRO Bank NV & NETHERLANDS & & & $x$ & \\
\hline Allied Irish Banks PLC & IRELAND & $\times$ & & $x$ & $\times$ \\
\hline Alpha Bank AE & GREECE & $x$ & $x$ & $x$ & \\
\hline Banca Monte dei Paschi di Siena SpA & ITALY & $x$ & $x$ & $x$ & $x$ \\
\hline Banca Popolare di Milano Scarl & ITALY & & & $x$ & \\
\hline Banco Bilbao Vizcaya Argentaria SA & SPAIN & $x$ & $x$ & $\times$ & $x$ \\
\hline Banco BPI SA & PORTUGAL & $x$ & $x$ & $x$ & \\
\hline Banco Comercial Portugues SA & PORTUGAL & $\times$ & $x$ & $x$ & \\
\hline Banco de Sabadell SA & SPAIN & $x$ & $x$ & $x$ & $x$ \\
\hline Banco Popolare SC & ITALY & $x$ & $x$ & $x$ & $x$ \\
\hline Banco Popular Espanol SA & SPAIN & $x$ & $x$ & $x$ & $x$ \\
\hline Banco Santander SA & SPAIN & $x$ & $x$ & $x$ & $x$ \\
\hline
\end{tabular}




\begin{tabular}{|c|c|c|c|c|c|}
\hline Bank of Ireland & IRELAND & $x$ & $x$ & $x$ & $x$ \\
\hline Bankinter SA & SPAIN & $x$ & $x$ & $x$ & \\
\hline Barclays Bank PLC & BRITAIN & $x$ & $x$ & $x$ & $x$ \\
\hline BAWAG PSK Bank fuer Arbeit und Wirtschaft und OP AG & AUSTRIA & & & $x$ & \\
\hline Bayerische Landesbank & GERMANY & $x$ & $x$ & $x$ & $x$ \\
\hline BNP Paribas SA & FRANCE & $x$ & $x$ & $x$ & $x$ \\
\hline Caixa Geral de Depositos SA & PORTUGAL & $x$ & $x$ & $x$ & \\
\hline Caja de Ahorros del Mediterraneo & SPAIN & $x$ & $x$ & & \\
\hline Commerzbank AG & GERMANY & $x$ & $x$ & $x$ & $x$ \\
\hline Cooperatieve Rabobank UA & NETHERLANDS & $x$ & $x$ & Pat & \\
\hline Credit Agricole SA & FRANCE & $x$ & $x$ & $x$ & $x$ \\
\hline Danske Bank A/S & DENMARK & $x$ & $x$ & $x$ & $x$ \\
\hline Deutsche Bank AG & GERMANY & $x$ & $x$ & $x$ & $x$ \\
\hline DNB Bank ASA & NORWAY & $x$ & $x$ & $x$ & $x$ \\
\hline DZ Bank AG Deutsche Zentral-Genossenschaftsbank & GERMANY & $x$ & $x$ & $x$ & \\
\hline Erste Group Bank AG & AUSTRIA & $x$ & $x$ & $x$ & $x$ \\
\hline Eurobank Ergasias SA & GREECE & rat & & $x$ & \\
\hline HSBC Bank PLC & BRITAIN & $x$ & $x$ & $x$ & $x$ \\
\hline HSH Nordbank AG & GERMANY & $x$ & $x$ & $x$ & \\
\hline IKB Deutsche Industriebank AG & GERMANY & & & $x$ & \\
\hline ING Bank NV & NETHERLANDS & $x$ & $x$ & $x$ & $x$ \\
\hline Intesa Sanpaolo SpA & ITALY & $x$ & $x$ & $x$ & $x$ \\
\hline KBC Group NV & BELGIUM & $x$ & $x$ & $x$ & $x$ \\
\hline Landesbank Baden-Wuerttemberg & GERMANY & $x$ & $x$ & $x$ & $x$ \\
\hline Landesbank Hessen-Thueringen Girozentrale & GERMANY & & & $x$ & $x$ \\
\hline Lloyds Bank PLC & BRITAIN & $x$ & $x$ & $x$ & $x$ \\
\hline Mediobanca Banca di Credito Finanziario SpA & ITALY & & & $\times$ & \\
\hline National Bank of Greece SA & GREECE & & & $x$ & \\
\hline Norddeutsche Landesbank Girozentrale & GERMANY & & & $x$ & $x$ \\
\hline Nordea Bank AB & SWEDEN & $x$ & $x$ & $x$ & $x$ \\
\hline Permanent TSB Group Holdings PLC & IRELAND & & & $x$ & \\
\hline Piraeus Bank SA & GREECE & & & $x$ & \\
\hline Raiffeisen Zentralbank Oesterreich AG & AUSTRIA & $x$ & $x$ & $x$ & \\
\hline Royal Bank of Scotland PLC/The & BRITAIN & $x$ & $x$ & $x$ & $x$ \\
\hline Skandinaviska Enskilda Banken AB & SWEDEN & $x$ & $x$ & $x$ & $x$ \\
\hline Societe Generale SA & FRANCE & $x$ & $x$ & $x$ & $x$ \\
\hline Svenska Handelsbanken AB & SWEDEN & $x$ & $x$ & $x$ & $x$ \\
\hline Swedbank AB & SWEDEN & $x$ & $x$ & $x$ & $x$ \\
\hline UniCredit SpA & ITALY & $x$ & $x$ & $x$ & $x$ \\
\hline Unione di Banche Italiane SpA & ITALY & $x$ & $x$ & $x$ & $x$ \\
\hline \multicolumn{2}{|l|}{ Total Number of participating banks } & 41 & 40 & 50 & 33 \\
\hline
\end{tabular}

Sources: European Banking Authority (EBA) and Authors' calculation.

Notes: All the above companies are banks. 
Panel C: Different countries in the EU final sample

\begin{tabular}{|c|c|}
\hline Country & $\begin{array}{c}\text { Number } \\
\text { of banks }\end{array}$ \\
\hline Austria & 3 \\
Belgium & 1 \\
Britain & 4 \\
Denmark & 1 \\
France & 3 \\
Germany & 9 \\
Greece & 4 \\
Ireland & 3 \\
Italy & 7 \\
Netherlands & 3 \\
Norway & 1 \\
Portugal & 3 \\
Spain & 6 \\
Sweden & 4 \\
\hline Total number of & $\mathbf{5 2}$ \\
participating banks & \\
\hline
\end{tabular}

Sources: European Banking Authority (EBA) and Authors' calculation. 
Appendix A.2: Summary statistics of the absolute Bid-Ask spreads (CDS liquidity proxy).

The summary statistics below are computed at the aggregate level (considering all tested banks), over the period from 2008 to 2017 in the US and from 2009 to 2016 in Europe. In each Panel, $\mathbf{N}$ is the number of observations. Mean (SD) is the average (standard deviation). CV is the Coefficient of variation (also known as relative standard deviation) which is the ratio of the standard deviation to the mean. Min is the Minimum while Max is the Maximum. pX corresponds to the Xth percentile.

Panel A: Summary statistics of the absolute Bid-Ask spreads in the US.

\begin{tabular}{|c|c|c|c|c|c|c|c|c|c|c|c|c|c|c|c|c|c|}
\hline Bank Name & Bank Country & Maturity & $\mathrm{N}$ & Mean & SD & $\mathrm{CV}$ & Min & Max & p1 & p5 & p10 & p25 & p50 & p75 & p90 & p95 & p99 \\
\hline \multirow{9}{*}{$\begin{array}{l}\text { All US } \\
\text { Banks }\end{array}$} & \multirow{9}{*}{ US } & 0,5 & 25008 & 18,9506 & 30,1412 & 1,59051 & 0,5 & 1312 & 2,99 & 4 & 4,94 & 7,12 & 11,23 & 22,48 & 40 & 53,22 & 92,29 \\
\hline & & 1 & 28319 & 22,5354 & 71,2031 & 3,15962 & 0,4 & 8175 & 3,97 & 4,26 & 5 & 8,05 & 12 & 22,32 & 40 & 51,7 & 193 \\
\hline & & 2 & 28319 & 18,2523 & 59,0945 & 3,23764 & 0,5 & 7027 & 4 & 4,21 & 5 & 7,28 & 10 & 20 & 32,62 & 40 & 115 \\
\hline & & 3 & 28319 & 15,8835 & 53,4654 & 3,3661 & 0 & 6186 & 4 & 4,21 & 5 & 7 & 10 & 16,22 & 29,25 & 35,74 & 85 \\
\hline & & 4 & 28319 & 13,9323 & 50,3228 & 3,61196 & 0 & 5820 & 3,89 & 4,57 & 5 & 5,89 & 10 & 14,99 & 22,08 & 30 & 65 \\
\hline & & 5 & 28319 & 9,68865 & 49,2589 & 5,08418 & 1 & 5746 & 2,99 & 3 & 3,32 & 4,64 & 5 & 10 & 15 & 20 & 40 \\
\hline & & 7 & 28319 & 15,0856 & 52,5545 & 3,48375 & 0 & 6176 & 4 & 5 & 5 & 7,18 & 10 & 15 & 24 & 36 & 73,17 \\
\hline & & 10 & 28317 & 16,7581 & 55,8751 & 3,33421 & 0 & 6827 & 3,06 & 5 & 5 & 8 & 10 & 18 & 27,22 & 40 & 96,47 \\
\hline & & All & 223239 & 16,3478 & 54,2086 & 3,31596 & 0 & 8175 & 3 & 4 & 4,97 & 6,24 & 10 & 16,71 & 30 & 40 & 94,64 \\
\hline
\end{tabular}

Sources: Authors' calculation.

Panel B: Summary statistics of the absolute Bid-Ask spreads in Europe.

\begin{tabular}{|c|c|c|c|c|c|c|c|c|c|c|c|c|c|c|c|c|c|}
\hline Bank Name & Country & Maturity & $\mathrm{N}$ & Mean & SD & $\mathrm{CV}$ & Min & Max & p1 & p5 & p10 & p25 & p50 & p75 & p90 & p95 & p99 \\
\hline \multirow{9}{*}{$\begin{array}{l}\text { All EU } \\
\text { Banks }\end{array}$} & \multirow{9}{*}{ Europe } & 0,5 & 96157 & 60,8679 & 187,205 & 3,07559 & 0,02 & 6825,04 & 2,27 & 4,07 & 5,45 & 9,16 & 18,31 & 43,18 & 100 & 264,23 & 774,86 \\
\hline & & 1 & 96029 & 57,3397 & 160,705 & 2,80269 & 0,16 & 4877,23 & 2,9 & 4,5 & 6,03 & 9,95 & 17,99 & 42,36 & 96,34 & 246,67 & 732,29 \\
\hline & & 2 & 96531 & 53,1263 & 183,357 & 3,45134 & 0,04 & 5135,18 & 3,28 & 5 & 6,75 & 10,36 & 17,55 & 36,68 & 74,37 & 192,95 & 712,55 \\
\hline & & 3 & 99735 & 47,9896 & 193,794 & 4,03826 & 0,07 & 8502,74 & 3,13 & 5 & 6,41 & 10 & 16,29 & 30 & 56,43 & 137,11 & 749,54 \\
\hline & & 4 & 95786 & 43,9659 & 181,327 & 4,12427 & 0,21 & 9593,92 & 4,03 & 5,13 & 6,14 & 9,37 & 15,15 & 26,89 & 50,43 & 118,98 & 645,05 \\
\hline & & 5 & 99749 & 39,5246 & 179,076 & 4,53075 & 0,37 & 11213,4 & 3,19 & 4,29 & 5 & 7 & 10,29 & 22 & 49,51 & 100 & 590,28 \\
\hline & & 7 & 96486 & 45,6057 & 328,789 & 7,20938 & 0,17 & 15194,1 & 3,69 & 4,92 & 6,4 & 9,43 & 14,43 & 25 & 48 & 98,3 & 586,47 \\
\hline & & 10 & 99747 & 42,7229 & 220,166 & 5,15333 & 0,4 & 10789 & 3,74 & 5 & 6,68 & 9,71 & 14,66 & 23,46 & 47,07 & 87,52 & 621,98 \\
\hline & & All & 780220 & 48,8188 & 210,259 & 4,30692 & 0,02 & 15194,1 & 3,14 & 4,82 & 5,69 & 9,67 & 15,67 & 30 & 62,01 & 143,22 & 703,89 \\
\hline
\end{tabular}

Sources: Authors' calculation. 
Panel C: Summary statistics of the absolute Bid-Ask spreads of the Markit CDX North America Investment Grade Index.

\begin{tabular}{|c|c|c|c|c|c|c|c|c|c|c|c|c|c|c|c|c|c|}
\hline Index Name & Index Country & Maturity & $\mathrm{N}$ & Mean & SD & $\mathrm{CV}$ & Min & Max & $\mathrm{p} 1$ & p5 & p10 & p25 & p50 & p75 & p90 & p95 & p99 \\
\hline \multirow{6}{*}{$\begin{array}{c}\text { Markit CDX } \\
\text { North } \\
\text { America } \\
\text { Investment } \\
\text { Grade Index }\end{array}$} & \multirow{6}{*}{ US } & 3 & 2490 & 1,921578 & 1,348725 & 0,70188 & 0 & 8 & 0,33 & 0,37 & 0,44 & 0,53 & 2 & 3 & 3,415 & 4,46 & 5,76 \\
\hline & & 4 & 2488 & 1,315215 & 0,766506 & 0,58280 & 0 & 6,5 & 0,404999 & 0,435001 & 0,470001 & 0,525002 & 1,25 & 1,790001 & 2,375 & 2,5 & 3,375 \\
\hline & & 5 & 2602 & 0,73869 & 0,503494 & 0,68160 & 0 & 6,97 & 0,34 & 0,45 & 0,48 & 0,5 & 0,5 & 0,89 & 1,06 & 2 & 2,9 \\
\hline & & 7 & 1767 & 1,957731 & 0,98573 & 0,50351 & 0,44 & 15,27 & 0,51 & 0,61 & 0,9 & 1,07 & 2 & 2,5 & 3,07 & 3,53 & 4,37 \\
\hline & & 10 & 2528 & 1,70481 & 1,152964 & 0,67630 & 0 & 8,13 & 0,45 & 0,5 & 0,58 & 1 & 1,5 & 2 & 3,04 & 4,2 & 6,12 \\
\hline & & All & 11875 & 1,494579 & 1,09491 & 0,73259 & 0 & 15,27 & 0,35 & 0,45 & 0,5 & 0,529999 & 1,14 & 2 & 3 & 3,5 & 5 \\
\hline
\end{tabular}

Sources: Authors' calculation.

Panel D: Summary statistics of the absolute Bid-Ask spreads of the Markit iTraxx Europe Investment Grade index.

\begin{tabular}{|c|c|c|c|c|c|c|c|c|c|c|c|c|c|c|c|c|c|}
\hline Index Name & Index Country & Maturity & $\mathrm{N}$ & Mean & SD & $\mathrm{CV}$ & Min & Max & p1 & p5 & p10 & p25 & p50 & p75 & p90 & p95 & p99 \\
\hline \multirow{6}{*}{$\begin{array}{c}\text { Markit iTraxx } \\
\text { Europe } \\
\text { Investment } \\
\text { Grade index }\end{array}$} & \multirow{6}{*}{ Europe } & 3 & 2085 & 1,212782 & 0,733526 & 0,60483 & 0 & 5,17 & 0,39 & 0,47 & 0,51 & 0,59 & 1 & 1,71 & 2 & 2,98 & 3,29 \\
\hline & & 4 & 2082 & 0,967752 & 0,452027 & 0,46709 & 0 & 4,169998 & 0,445 & 0,499996 & 0,510002 & 0,560005 & 0,879997 & 1,215 & 1,5 & 1,830002 & 2,300003 \\
\hline & & 5 & 2083 & 0,722357 & 0,289346 & 0,40056 & 0 & 3,17 & 0,43 & 0,5 & 0,5 & 0,5 & 0,66 & 0,9 & 1 & 1 & 2 \\
\hline & & 7 & 2084 & 1,19844 & 0,87662 & 0,73147 & 0 & 7,45 & 0,44 & 0,44 & 0,47 & 0,555 & 1 & 1,5 & 2 & 2,51 & 5,42 \\
\hline & & 10 & 2083 & 1,133735 & 0,729253 & 0,64323 & 0 & 6,36 & 0,38 & 0,43 & 0,44 & 0,56 & 1 & 1,5 & 2 & 2,21 & 4,9 \\
\hline & & All & 10417 & 1,047067 & 0,677581 & 0,64712 & 0 & 7,45 & 0,400002 & 0,46 & 0,494995 & 0,54 & 0,94 & 1,23999 & 1,96 & 2,09 & 3,38 \\
\hline
\end{tabular}

Sources: Authors' calculation. 
Appendix A.3: Summary statistics of tested banks' CDS MID spreads.

The summary statistics below are computed at the aggregate level (considering all tested banks), over the period from 2008 to 2017 in the US and from 2009 to 2016 in Europe. In each Panel, $\mathbf{N}$ is the number of observations. Mean (SD) is the average (standard deviation). CV is the Coefficient of variation (also known as relative standard deviation) which is the ratio of the standard deviation to the mean. Min is the Minimum while Max is the Maximum. $\mathbf{p X}$ corresponds to the Xth percentile.

Panel A: Summary statistics of tested banks' CDS MID spreads in the US (at the aggregate level).

\begin{tabular}{|c|c|c|c|c|c|c|c|c|c|c|c|c|c|c|c|c|}
\hline Country & Maturity & $\mathrm{N}$ & Mean & SD & $\mathrm{CV}$ & Min & Max & p1 & p5 & p10 & p25 & p50 & p75 & p90 & p95 & p99 \\
\hline \multirow{9}{*}{ US } & 0,5 & 25008 & 65,0169 & 144,215 & 2,21812 & 2,79 & 8305,8 & 6 & 8,03 & 10,26 & 16 & 27,54 & 62,4075 & 141,615 & 242,51 & 525,91 \\
\hline & 1 & 28319 & 116,286 & 349,519 & 3,00569 & 0,4 & 10427,2 & 7,53 & 11 & 14 & 23,24 & 39,115 & 89,48 & 238,975 & 426,335 & 1177,9 \\
\hline & 2 & 28319 & 125,719 & 315,97 & 2,51331 & 0,5 & 10273,1 & 11,765 & 17,5 & 21,855 & 34,075 & 51,45 & 113 & 253,5 & 412,085 & 1144,3 \\
\hline & 3 & 28319 & 134,817 & 291,533 & 2,16243 & 0,6 & 9868,1 & 16,425 & 25 & 30,48 & 43,805 & 66,435 & 132 & 262,5 & 404,69 & 1071,5 \\
\hline & 4 & 28319 & 143,749 & 274,128 & 1,90699 & 0,8 & 9652 & 21,98 & 33,5 & 39,5 & 53,295 & 79,715 & 147,52 & 266,61 & 398,7 & 1041 \\
\hline & 5 & 28319 & 153,779 & 261,125 & 1,69805 & 1 & 9526,8 & 28,415 & 42,27 & 48,82 & 65 & 93,895 & 161,68 & 277,175 & 395,05 & 1000,5 \\
\hline & 7 & 28319 & 163,082 & 239,573 & 1,46904 & 3,7 & 9273 & 42,095 & 56,095 & 61,625 & 80 & 109,9 & 172,86 & 282,55 & 381,6 & 912,7 \\
\hline & 10 & 28317 & 169,873 & 220,369 & 1,29726 & 7,4 & 8978,7 & 51,85 & 64,01 & 70,33 & 91,05 & 122 & 180,5 & 288,33 & 375,47 & 846,9 \\
\hline & All & 223239 & 135,064 & 271,675 & 2,01146 & 0,4 & 10427,2 & 8,57 & 16 & 23,305 & 43,16 & 79,58 & 140 & 261,66 & 385,885 & 956,1 \\
\hline
\end{tabular}

Sources: Authors' calculation.

Panel B: Summary statistics of tested banks' CDS MID spreads in Europe (at the aggregate level).

\begin{tabular}{|c|c|c|c|c|c|c|c|c|c|c|c|c|c|c|c|c|}
\hline Country & Maturity & $\mathrm{N}$ & Mean & SD & $\mathrm{CV}$ & Min & Max & $\mathrm{p} 1$ & p5 & p10 & p25 & p50 & p75 & p90 & p95 & p99 \\
\hline \multirow{9}{*}{ Europe } & 0,5 & 96157 & 233,044 & 617,463 & 2,64956 & 2,325 & 21501,7 & 6,02 & 12,42 & 17,29 & 31,2 & 74,21 & 178,88 & 498,005 & 900,185 & 3205,12 \\
\hline & 1 & 96029 & 243,174 & 550,367 & 2,26326 & 4,15 & 18240,8 & 9,64 & 16,765 & 21,59 & 37 & 85,945 & 203,865 & 534,9 & 975,35 & 2984,86 \\
\hline & 2 & 96531 & 245,068 & 460,199 & 1,87784 & 8,285 & 13264,2 & 18,2 & 27,78 & 33,61 & 52,91 & 104,93 & 230,225 & 545,55 & 952,69 & 2363,28 \\
\hline & 3 & 99735 & 253,717 & 467,019 & 1,84071 & 12,965 & 10976,7 & 26,34 & 37,515 & 44,305 & 64,09 & 119,115 & 242,54 & 539,97 & 966,72 & 2180,81 \\
\hline & 4 & 95786 & 267,709 & 422,24 & 1,57724 & 22,525 & 9597,92 & 40,98 & 50,68 & 58,155 & 81,105 & 139,353 & 270,9 & 570,91 & 967,01 & 2033,88 \\
\hline & 5 & 99749 & 266,896 & 391,605 & 1,46725 & 26,5 & 10066,1 & 47,84 & 58 & 65,79 & 88,4 & 150 & 272,505 & 555,38 & 933,48 & 1888,24 \\
\hline & 7 & 96486 & 273,43 & 405,347 & 1,48245 & 32,95 & 10449,7 & 57,12 & 68,86 & 77,805 & 101,84 & 163 & 280,55 & 557,765 & 896,14 & 1676,42 \\
\hline & 10 & 99747 & 274,29 & 358,839 & 1,30825 & 39,19 & 10492,5 & 61,685 & 75,14 & 84,475 & 109,55 & 173,14 & 288,495 & 550 & 836,26 & 1626,07 \\
\hline & All & 780220 & 257,272 & 465,656 & 1,80998 & 2,325 & 21501,7 & 13,01 & 26,16 & 39,71 & 72 & 129,41 & 249,885 & 545,655 & 923,285 & 2179,71 \\
\hline
\end{tabular}

Sources: Authors' calculation. 


\section{Appendix A.4: Summary statistics of indexes' MID spreads.}

The summary statistics below are computed over the period from 2008 to 2017 in the US and from 2009 to 2016 in Europe. In each Panel, $\mathbf{N}$ is the number of observations. Mean (SD) is the average (standard deviation). CV is the Coefficient of variation (also known as relative standard deviation) which is the ratio of the standard deviation to the mean. Min is the Minimum while Max is the Maximum. pX corresponds to the Xth percentile.

Panel A: Summary statistics of the Markit CDX North America Investment Grade Index' MID spreads.

\begin{tabular}{|c|c|c|c|c|c|c|c|c|c|c|c|c|c|c|c|c|c|}
\hline Index_Name & Index_Country & Maturity & $\mathrm{N}$ & Mean & SD & $\mathrm{CV}$ & Min & Max & p1 & p5 & p10 & p25 & p50 & p75 & p90 & p95 & p99 \\
\hline \multirow{6}{*}{$\begin{array}{c}\text { Markit CDX } \\
\text { North } \\
\text { America } \\
\text { Investment } \\
\text { Grade Index }\end{array}$} & \multirow{6}{*}{ US } & 3 & 2490 & 67,47591 & 46,46569 & 0,68863 & 25,41 & 295,23 & 26,35 & 29,3 & 31,875 & 37,72 & 53,3425 & 77,92 & 111,4275 & 186,5 & 254,03 \\
\hline & & 4 & 2488 & 80,4613 & 40,77578 & 0,50678 & 36,945 & 281,44 & 39,545 & 43,815 & 46,6025 & 52,76625 & 69,58375 & 90,7575 & 120,145 & 183,02 & 247,13 \\
\hline & & 5 & 2602 & 96,04323 & 37,73439 & 0,39289 & 48,48 & 279,74 & 52,6 & 57,77 & 61,99 & 69,25 & 86,9 & 108,5 & 140,35 & 185,75 & 237,27 \\
\hline & & 7 & 1767 & 103,2356 & 17,44471 & 0,16898 & 71,49 & 166,38 & 74,775 & 78,93 & 83,93 & 89,825 & 100,205 & 113,25 & 129,17 & 137,655 & 149,21 \\
\hline & & 10 & 2528 & 122,4445 & 19,67266 & 0,16067 & 85,92 & 242,52 & 92,91 & 99,575 & 103 & 109,0875 & 118,49 & 130,7175 & 147,17 & 157,47 & 193,16 \\
\hline & & All & 11875 & 93,4791 & 40,14821 & 0,42949 & 25,41 & 295,23 & 29,25 & 37,425 & 46,19 & 63,78 & 91,5 & 114,675 & 136,64 & 156,57 & 231,22 \\
\hline
\end{tabular}

Sources: Authors' calculation.

Panel B: Summary statistics of the Markit iTraxx Europe Investment Grade index' MID spreads.

\begin{tabular}{|c|c|c|c|c|c|c|c|c|c|c|c|c|c|c|c|c|c|}
\hline Index_Name & Index_Country & Maturity & $\mathrm{N}$ & Mean & SD & $\mathrm{CV}$ & Min & Max & p1 & p5 & p10 & p25 & p50 & p75 & p90 & p95 & p99 \\
\hline \multirow{6}{*}{$\begin{array}{c}\text { Markit iTraxx } \\
\text { Europe } \\
\text { Investment } \\
\text { Grade index }\end{array}$} & \multirow{6}{*}{ Europe } & 3 & 2085 & 75,82818 & 40,48944 & 0,53396 & 27,75 & 238,63 & 30,17 & 33,795 & 37,5 & 44,625 & 66,555 & 91,34 & 144,34 & 164,96 & 199,89 \\
\hline & & 4 & 2082 & 88,52629 & 37,58626 & 0,42458 & 37,935 & 222,73 & 42,205 & 46,57 & 50,3225 & 58,605 & 80,80875 & 104,8925 & 156,025 & 168,545 & 192,745 \\
\hline & & 5 & 2083 & 101,2772 & 35,57937 & 0,35131 & 47,74 & 208,37 & 53 & 59,1 & 63,125 & 72,605 & 95,68 & 118,96 & 162,02 & 176,13 & 196,67 \\
\hline & & 7 & 2084 & 116,3301 & 31,43749 & 0,27024 & 64,63 & 218,6 & 70,03 & 78,525 & 82,92 & 91,9125 & 108,7575 & 136,6175 & 162,55 & 182,925 & 199,97 \\
\hline & & 10 & 2083 & 127,5113 & 28,9194 & 0,22680 & 79,665 & 224,94 & 84,25 & 91,38 & 96,235 & 106,29 & 119,62 & 147 & 169,955 & 187,785 & 205,68 \\
\hline & & Total & 10417 & 101,8923 & 39,65891 & 0,38922 & 27,75 & 238,63 & 33,795 & 43,6475 & 52,5 & 71,955 & 97,685 & 125,805 & 159,525 & 177,67 & 198,84 \\
\hline
\end{tabular}

Sources: Authors' calculation. 
